ZRC SAZU, UMETNOSTNOZGODOVINSKI INŠTITUT FRANCETA STELETA

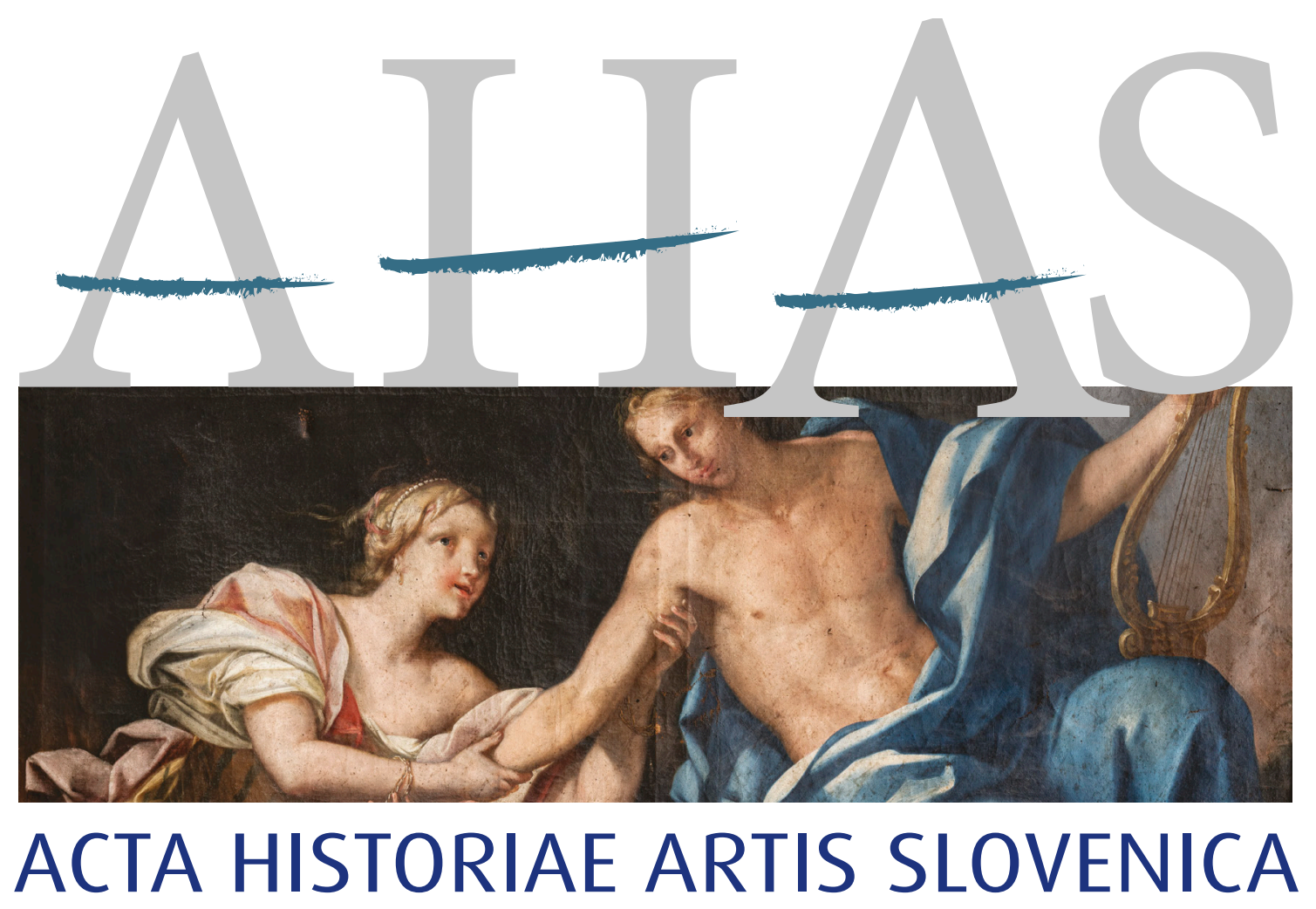

Frančišek Karel Remb in slikarstvo

v habsburških dednih deželah okrog leta 1700

Franz Carl Remp and Painting in the Habsburg Hereditary Lands around 1700

Franz Carl Remp und die Malerei in den habsburgischen Erblanden um 1700

$$
26 \mid 2 \cdot 2021
$$




\section{ACTA HISTORIAE ARTIS SLOVENICA $26 \mid 2 \cdot 2021$}

Frančišek Karel Remb in slikarstvo v habsburških dednih deželah okrog leta 1700

Franz Carl Remp and Painting in the Habsburg Hereditary Lands around 1700

Franz Carl Remp und die Malerei in den habsburgischen Erblanden um 1700 
Acta historiae artis Slovenica, 26/2, 2021

Frančišek Karel Remb in slikarstvo v habsburških dednih deželah okrog leta 1700

Franz Carl Remp and Painting in the Habsburg Hereditary Lands around 1700

Franz Carl Remp und die Malerei in den habsburgischen Erblanden um 1700

Znanstvena revija za umetnostno zgodovino / Scholarly Journal for Art History

ISSN 1408-0419 (tiskana izdaja / print edition) ISSN 2536-4200 (spletna izdaja / web edition)

ISBN 978-961-05-0568-6

Izdajatelj / Issued by

ZRC SAZU, Umetnostnozgodovinski inštitut Franceta Steleta /

ZRC SAZU, France Stele Institute of Art History

Založnik / Publisher

Založba ZRC

Urednika / Edited by

Edgar Lein, Polona Vidmar

Uredniški odbor / Editorial board

Renata Komić Marn, Tina Košak, Katarina Mohar, Mija Oter Gorenčič, Blaž Resman, Helena Seražin

Mednarodni svetovalni odbor / International advisory board

Günter Brucher (Salzburg), Ana María Fernández García (Oviedo), Hellmut Lorenz (Wien),

Milan Pelc (Zagreb), Sergio Tavano (Gorizia-Trieste), Barbara Wisch (New York)

Lektoriranje / Language editing

Oliver Currie, Manuela Dajnko, Andrea Leskovec

Prevodi / Translations

Alan Harvey Cook, Blaž Resman, Nika Vaupotič, Polona Vidmar

Celostni strokovni in jezikovni pregled / Expert and language editing

Blaž Resman

Oblikovna zasnova in prelom / Design and layout

Andrej Furlan

Naslov uredništva / Editorial office address

Acta historiae artis Slovenica

Novi trg 2, p. p. 306, SI -1001 Ljubljana, Slovenija

ahas@zrc-sazu.si; https://ojs.zrc-sazu.si/ahas

Revija je indeksirana v / Journal is indexed in

Scopus, ERIH PLUS, EBSCO Publishing, IBZ, BHA

Letna naročnina / Annual subscription: $35 €$

Posamezna enojna številka / Single issue: $25 €$

Letna naročnina za študente in dijake: $25 €$

Letna naročnina za tujino in ustanove / Annual subscription outside Slovenia, institutions: $48 €$

Naročila sprejema / For orders contact

Založba ZRC

Novi trg 2, p. p. 306, SI-1001, Slovenija

E-pošta / E-mail: zalozba@zrc-sazu.si

AHAS izhaja s podporo Javne agencije za raziskovalno dejavnost Republike Slovenije.

AHAS is published with the support of the Slovenian Research Agency.

(c) 2021, ZRC SAZU, Umetnostnozgodovinski inštitut Franceta Steleta, Založba ZRC, Ljubljana Tisk / Printed by Collegium Graphicum d.o.o., Ljubljana

Naklada / Print run: 400 


\section{VSEBINA \\ Contents}

Edgar Lein, Polona Vidmar

Frančišek Karel Remb in slikarstvo v habsburških dednih deželah okrog leta 1700. Predgovor ...........................5

Franz Carl Remp and Painting in the Habsburg Hereditary Lands around 1700. Preface .....................................7

Franz Carl Remp und die Malerei in den habsburgischen Erblanden um 1700. Vorwort .....................................9

\section{DISSERTATIONES}

Karin Požin

Remp's Ceiling Paintings in the Palais Attems in Graz. From Reproductive Prints to Frescoes

Rembove stropne poslikave v graški palači Attems. Od grafičnih predlog do fresk ...13

Georg Lechner

Franz Carl Remp zwischen Graz und Wien 31

Frančišek Karel Remb med Gradcem in Dunajem 48

Edgar Lein

Preis und Wert der Malerei um 1700. Zu den Kosten von Gemälden in der Steiermark 51

Cena in vrednost slik okrog leta 1700. O stroških za slike na Štajerskem

Renata Komić Marn

Zaplemba - prenos - distribucija. Slike grofa Attemsa iz gradu Slovenska Bistrica $v$ slovenskih javnih zbirkah

Confiscation - Transfer - Distribution. Count Attems' Paintings from

Slovenska Bistrica Castle in Slovenian Public Collections

Polona Vidmar

Emblematische Gratulationsschriften, Stammbäume und Porträts

von Dominik Franz Calin von Marienberg für das Haus Habsburg.

Emblematična voščila, rodovniki in portreti Dominika Frančiška Kalina

von Marienberga za Habsburžane

Ulrich Becker

Weltgeschichte im Wimmelbild. Stephan Kessler und der Entsatz von Wien 1683.

Svetovna zgodovina na »mrgoleči sliki«. Stephan Kessler in Rešitev Dunaja leta 1683 
Andreas Gamerith

Zeit des Experiments. Die Galleria maior des Stiftes Zwettl als Beispiel

für seicenteske Wandmalerei in Niederösterreich.

Čas eksperimentiranja. Galleria maior v samostanu Zwettl

kot primer stenskega slikarstva 17. stoletja v Spodnji Avstriji

\section{Martin Mádl}

The Patterns of the Transformation in Central European Ceiling Painting

around 1700 and Franz Carl Remp in Brežice Castle.

Vzorci transformacije v srednjeevropskem stropnem slikarstvu okrog leta 1700

in Frančišek Karel Remb v brežiškem gradu 


\section{Predgovor}

\section{FranČIŠEK KAREL REMB IN SLIKARSTVO V HABSBURŠKIH DEDNIH DEŽELAH OKROG LETA 1700}

Kljub razmeroma številnim slikam je ostal opus v Radovljici rojenega ter v Gradcu in na Dunaju delujočega slikarja Frančiška Karla Remba (1675-1718) široki javnosti doslej večinoma neznan. Prva in zaenkrat edina razstava Rembovih del je bila od 26. oktobra 1973 do 19. maja 1974 na ogled v Spodnjem Belvederu na Dunaju ter junija 1974 v vogalni sobi Stare galerije muzeja Joanneum v graški Neutorgasse. Razstavni katalog z naslovom Der Barockmaler Franz Carl Remp 1674-1718 vsebuje sedem strani obsegajoč uvod v umetnikovo življenje in delo, kataložni del z dvajsetimi enotami, časovnico in seznam literature.

Georg Lechner se je s Frančiškom Karlom Rembom ukvarjal v okviru svoje leta 2010 na Dunaju obranjene doktorske disertacije. Ko je spomladi 2018 Lechner opozoril, da se jeseni bliža tristota obletnica Rembove smrti, vendar ni niti na Dunaju niti v Gradcu načrtovana kakšna razstava slikarjevih del, smo se odločili za organizacijo simpozija, ki je pod naslovom Slikarji in naročniki. Frančišek Karel Remb in slikarstvo na Štajerskem okrog 1700 potekal 23. novembra 2018 v Laterneng'wölb dvorca Eggenberg. Naslednji dan so si udeleženci pod vodstvom Georga Lechnerja ogledali palačo Attems in pod vodstvom Paula Schusterja reprezentativne prostore dvorca Eggenberg. Simpozij so podprli univerzi v Gradcu in Mariboru ter Znanstvenoraziskovalni center Slovenske akademije znanosti in umetnosti, Umetnostnozgodovinski inštitut Franceta Steleta. Bil je del bilateralnega projekta BI SLO-AT/16-17-18: Umetnostni naročniki kot nosilci deželne identitete. Vloga in pomen naročnikov za gradnjo in opremo plemiških rezidenc in romarskih središč na Štajerskem, ki sta ga financirala Javna agencija za raziskovalno dejavnost Republike Slovenije in Österreichischer Austauschdienst, ter temeljnega raziskovalnega projekta J6-7410: Umetnostna reprezentacija plemstva. Naročništvo na Štajerskem $v$ zgodnjem novem veku (2016-2018), ki ga je financirala Javna agencija za raziskovalno dejavnost Republike Slovenije.

Simpozij so otvorili Georg Lechner s temeljnim prispevkom o Frančišku Karlu Rembu med Gradcem in Dunajem (Franz Carl Remp zwischen Graz und Wien), Christine Rabensteiner, ki je predstavila dela priseljenih in na Štajerskem rojenih baročnih slikarjev v depojih graške Stare galerije (Werke immigrierter und gebürtiger steirischer Barockmaler. Ein Blick in das Depot der Alten Galerie), ter Karin Požin s študijo o Rembovih stropnih poslikavah v palači Attems v Gradcu in likovnih virih zanje (Case Study of Remp's Ceiling Paintings in Palais Attems in Graz. From Reproductive Prints to Frescoes). V drugem delu je Edgar Lein predstavil ceno in vrednost slikarskih del okrog 1700 (Preis und Wert der Malerei um 1700), Tina Košak pa je na podlagi virov v mestnem arhivu v Antwerpnu raziskala trgovce $\mathrm{z}$ umetninami iz družine Forchondt in njihove štajerske stranke (The Forchondt Art Dealers and their Styrian Clients. Excerpts from the Antwerp City Archives). Renata Komić Marn je analizirala portrete Eleonore Marije Rozalije kneginje Eggenberg (The Portraits of Eleonora Maria Rosalia Princess of Eggenberg), Polona Vidmar pa je predstavila slikane genealogije štajerskega plemstva okrog leta 1700 (Gemalte Genealogien des steirischen Adels um 1700). Meje historične Štajerske so s svojimi referati presegli Ulrich Becker, ki je Stephanu Kesslerju pripisal upodobitvi Rešitve 
Dunaja leta 1683 (Weltgeschichte als Wimmelbild. Stephan Kessler und der Entsatz von Wien 1683), Andreas Gamerith, ki se je ukvarjal s stropnimi poslikavami pred Trogerjem oziroma okrog leta $1700 \mathrm{v}$ samostanih Zwettl in Altenburg (Vor Troger. Aspekte der Wandmalerei um 1700 am Beispiel der Klöster Zwettl und Altenburg), ter Martin Mádl z izčrpnim predavanjem o češkem stropnem slikarstvu okoli 1700 („So ist nun ... der Pracht im Bauen so hoch gestiegen ..... Profane Ceiling Painting in Bohemia around 1700).

Udeleženci simpozija so svoje referate pripravili za tisk ali pa so prispevali nova raziskovalna spoznanja, ki jih v Acta historiae artis Slovenica objavljamo pod naslovom Frančišek Karel Remb in slikarstvo v habsburških dednih deželah okrog leta 1700. Prispevka Karin Požin in Georga Lechnerja poglabljata vedenje o Rembovih stenskih poslikavah v palači Attems in o delih, ki jih je ustvaril po selitvi na Dunaj. Nekatere Rembove oljne slike so obravnavane tudi v prispevkih Edgarja Leina, ki se je posvetil stroškom za slike na Štajerskem, ter Renate Komić Marn, ki je raziskala slike iz Attemsove zbirke v Slovenski Bistrici v slovenskih javnih zbirkah. Slikarstvo zadnjih desetletij 17. stoletja je tema prispevkov Polone Vidmar, ki se je posvetila delom Dominika Frančiška Kalina von Marienberga za Habsburžane, in Ulricha Beckerja, ki je upodobitvi Rešitve Dunaja atribuiral tirolskemu slikarju Stephanu Kesslerju. Andreas Gamerith je Gallerio maior v samostanu Zwettl predstavil kot eksperiment v stropnem slikarstvu poznega 17. stoletja v Spodnji Avstriji, zvezek pa zaključuje prispevek Martina Mádla, ki se je posvetil transformaciji srednjeevropskega slikarstva okrog leta 1700 in pomembnim zgledom zanjo.

Upava, da bodo raznoliki prispevki in številne upodobitve spodbudili nadaljnje raziskovanje baročnega slikarstva. 


\section{Preface}

\section{Franz Carl Remp and Painting in THE HABSbURg Hereditary LANDS AROUND 1700}

The oeuvre of Radovljica born painter Franz Carl Remp (1675-1718) who worked in Graz and Vienna is little-known to the wider public despite his relatively numerous paintings. The first and only exhibition of Remp's works up to now was held from 26 October 1973 to 19 May 1974 at the Lower Belvedere in Vienna, and in the corner room of the present-day Universalmuseum Joanneum's Alte Galerie in Neutorgasse in Graz in June 1974. The exhibition catalogue entitled Der Barockmaler Franz Carl Remp 1674-1718 includes a seven-page introduction to the artist's life and work, a catalogue comprising twenty units, a chronology, and list of sources.

Georg Lechner researched Franz Carl Remp in his PhD thesis, which he defended 2010 in Vienna. In the spring of 2018, Lechner drew attention to the fact that the $300^{\text {th }}$ anniversary of the painter's death would occur in the autumn of the same year, and that neither Vienna nor Graz planned to commemorate the anniversary with an exhibition of the Baroque painter's works. We therefore decided to organize a conference entitled Painters and Patrons. Franz Carl Remp and Painting in Styria around 1700 that was held on 23 November 2018 at the Laterneng'wölb in the Eggenberg Castle. The following day the participants went on a tour of the Palais Attems, guided by Georg Lechner, as well as a tour of Eggenberg Castle's monumental rooms guided by Paul Schuster. The conference was supported by the Universities of Graz and Maribor, and the Research Centre of the Slovenian Academy of Sciences and Arts, the France Stele Institute of Art History. It formed part of the bilateral project BI SLO-AT/16-17-18: Art Patrons as Carriers of Province's Identity. The Role and Significance of Commissioners of Architectures and Furnishings of Aristocratic Residences and Pilgrimage Sites in Styria, which was financed by the Slovenian Research Agency and the Österreichischer Austauschdienst, and the research project J6-7410: Visual Representations of the Nobility. Early Modern Art Patronage in the Styria Province (2016-2018), financed by the Slovenian Research Agency.

The conference opened with Georg Lechner's general and foundational contribution - Franz Carl Remp between Graz and Vienna (Franz Carl Remp zwischen Graz und Wien) - followed by Christine Rabensteiner, who presented the works of immigrant and Styria-born Baroque painters in storage in the Alte Galerie in Graz (Werke immigrierter und gebürtiger steirischer Barockmaler. Ein Blick in das Depot der Alten Galerie), and Karin Požin with her study of Remp's ceiling paintings in Palais Attems in Graz and their sources (Case Study of Remp's Ceiling Paintings in Palais Attems in Graz. From Reproductive Prints to Frescoes). In the second part of the conference there were papers on the wider context and Styrian art of the period. Edgar Lein gave a spech on the cost and value of paintings around 1700 (Preis und Wert der Malerei um 1700). Tina Košak presented a study of the art dealers from the Forchondt family and their Styrian clients based on sources in the Antwerp city archives (The Forchondt Art Dealers and their Styrian Clients. Excerpts from the Antwerp City Archives). Renata Komić Marn analysed the portraits of Eleonora Maria Rosalia Princess of Eggenberg (The Portraits of Eleonora Maria Rosalia Princess of Eggenberg), and Polona Vidmar presented the painted genealogies of Styrian nobility around 1700 (Gemalte Genealogien des steirischen Adels um 
1700). The final section of the conference went beyond the borders of historical Styria: Ulrich Becker attributed the depictions of the Liberation of Vienna in 1683 to Stephan Kessler (Weltgeschichte als Wimmelbild. Stephan Kessler und der Entsatz von Wien 1683); Andreas Gamerith dealt with ceiling paintings in the Zwettl and Altenburg monasteries before Troger (Vor Troger. Aspekte der Wandmalerei um 1700 am Beispiel der Klöster Zwettl und Altenburg), and Martin Mádl gave a detailed paper on Czech ceiling painting around 1700 („So ist nun ... der Pracht im Bauen so hoch gestiegen .... Profane Ceiling Painting in Bohemia around 1700).

The conference participants prepared their papers for publication, or contributed new research findings, which are now being published in the Acta historiae artis Slovenica under the title Franz Carl Remp and Painting in the Habsburg Hereditary Lands around 1700. The contributions by Karin Požin and Georg Lechner deepen our knowledge of Remp's ceiling paintings in the Palais Attems, as well of the works he created after moving to Vienna. Some of Remp's oil paintings are also treated in the papers by Edgar Lein, who focuses on the cost of paintings in Styria, and by Renata Komić Marn, who discusses the paintings from the Attems collection in Slovenska Bistrica in Slovenian public collections. The topic of the papers by Polona Vidmar, who focuses on Dominik Franz Kalin von Marienberg's works for the Habsburg family, and Ulrich Becker, who attributes the depictions of the Liberation of Vienna to Tyrolian painter Stephan Kessler, is the painting of the last decades of the $17^{\text {th }}$ century. Andreas Gamerith discusses the Galleria maior in the Zwettl monastery as an experiment in ceiling painting in late $17^{\text {th }}$ century Lower Austria. The volume is concluded by Martin Mádl's contribution, which focuses on the transformation of Central European painting around 1700 and the models that were important for this transformation.

We hope that the diverse contributions and the numerous depictions will encourage further research in Baroque painting. 


\section{VORWORT}

\section{Franz CARl Remp UNd die MAlerei IN DEN HABSBURGISCHEN ERBLANDEN \\ UM 1700}

Trotz einer relativ großen Anzahl von Gemälden ist das CEuvre des in Radovljica in Slowenien geborenen und in Graz sowie Wien tätigen Malers Franz Carl Remp (1675-1718) einer breiten Öffentlichkeit bislang weitgehend unbekannt geblieben. Die erste und bislang einzige Ausstellung mit Werken des Malers wurde vom 26. Oktober 1973 bis zum 19. Mai 1974 im Unteren Belvedere in Wien und im Juni 1974 im Ecksaal der Alten Galerie des Joanneums in der Grazer Neutorgasse gezeigt. Das Katalogbändchen mit dem Titel Der Barockmaler Franz Carl Remp 1674-1718 enthält eine sieben Seiten umfassende Einführung zu Leben und Werk des Künstlers, einen Katalogteil mit zwanzig Einträgen, eine Zeittafel und ein Literaturverzeichnis.

Georg Lechner hat sich im Rahmen seiner 2010 in Wien abgeschlossenen Dissertation umfassend mit Franz Carl Remp befasst. Als Lechner im Frühjahr 2018 darauf hinwies, dass sich der 300. Todestag des Malers im Herbst nähere, aber weder in Wien noch in Graz eine Ausstellung mit Werken des Barockmalers geplant sei, beschlossen die Herausgeber, eine Tagung zu organisieren, die am 23. November 2018 unter dem Titel Maler und Auftraggeber. Franz Carl Remp und die Malerei in der Steiermark um 1700 im Laterneng'wölb von Schloss Eggenberg abgehalten wurde. Ergänzend dazu gab es am darauffolgenden Tag eine Besichtigung des Palais Attems unter der Leitung von Georg Lechner sowie eine Führung von Paul Schuster durch die Prunkräume von Schloss Eggenberg. Die von den Universitäten in Graz und Maribor sowie dem France Stele Institut für Kunstgeschichte am Forschungszentrum der Slowenischen Akademie der Wissenschaften und Künste unterstützte Veranstaltung war Teil des von der Slowenischen Forschungsagentur und dem Österreichischen Austauschdienst finanzierten bilateralen Projekts BI SLO-AT/16-17-18: Art Patrons as Carriers of Province's Identity. The Role and Significance of Commissioners of Architectures and Furnishings of Aristocratic Residences and Pilgrimage Sites in Styria sowie des von der Slowenischen Forschungsagentur finanzierten Forschungsprojekts J6-7410: Visual Representations of the Nobility. Early Modern Art Patronage in the Styria Province (2016-2018).

Den Anfang der Tagung machten Georg Lechner mit einem grundlegenden Vortrag über Franz Carl Remp zwischen Graz und Wien und Christine Rabensteiner mit Werke immigrierter und gebürtiger steirischer Barockmaler. Ein Blick in das Depot der Alten Galerie sowie Karin Požin mit einer Case Study of Remp's Ceiling Paintings in Palais Attems in Graz. From Reproductive Prints to Frescoes. Im zweiten Teil untersuchten Edgar Lein Preis und Wert der Malerei um 1700 und Tina Košak The Forchondt Art Dealers and their Styrian Clients. Excerpts from the Antwerp City Archives. Renata Komić Marn analysierte The Portraits of Eleonora Maria Rosalia Princess of Eggenberg und Polona Vidmar präsentierte Gemalte Genealogien des steirischen Adels um 1700. Den Blick über die Steiermark hinaus weiteten Ulrich Becker mit seinem Vortrag Weltgeschichte als Wimmelbild. Stephan Kessler und der Entsatz von Wien 1683, Andreas Gamerith mit einem Blick auf die Malerei Vor Troger. Aspekte der Wandmalerei um 1700 am Beispiel der Klöster Zwettl und Altenburg und Martin Mádl mit einem umfassenden Vortrag zum Thema „So ist nun ... der Pracht im Bauen so hoch gestiegen ..... Profane Ceiling Painting in Bohemia around 1700. 
Die Referenten und Referentinnen überarbeiteten ihre Vorträge für die Drucklegung oder präsentierten neue Forschungsergebnisse, die wir in den Acta historiae artis Slovenica unter dem Titel Franz Carl Remp und die Malerei in den habsburgischen Erblanden um 1700 veröffentlichen. Die Beiträge von Karin Požin und Georg Lechner erweitern das Wissen über Remps Wandmalereien im Palais Attems und über sein nach der Übersiedlung nach Wien geschaffenes Werk. Einige Ölgemälde Remps werden auch in den Beiträgen von Edgar Lein, der sich den Kosten für Gemälde in der Steiermark widmet, und Renata Komić Marn, die die Gemälde der ursprünglich in Schloss Slovenska Bistrica befindlichen Sammlung Attems in slowenischen öffentlichen Sammlungen untersucht, behandelt. Die Malerei in den letzten Jahrzehnten des 17. Jahrhunderts ist das Thema der Beiträge von Polona Vidmar, die die Werke Dominik Franz Calins von Marienberg für das Haus Habsburg präsentiert, und Ulrich Becker, der zwei Darstellungen des Entsatzes von Wien dem Tiroler Maler Stephan Kessler zuschreibt. Andreas Gamerith thematisiert die Galleria maior in Stift Zwettl als ein Experiment der Deckenmalerei des späten 17. Jahrhunderts in Niederösterreich. Der Band endet mit dem Beitrag von Martin Mádl, der sich der Transformation der mitteleuropäischen Wandmalerei um 1700 und ihren bedeutenden Vorbildern widmet.

Wir hoffen, dass die vielfältigen Beiträge und die zahlreichen Abbildungen zu einer weiteren Beschäftigung mit der Barockmalerei anregen werden.

Edgar Lein, Polona Vidmar 


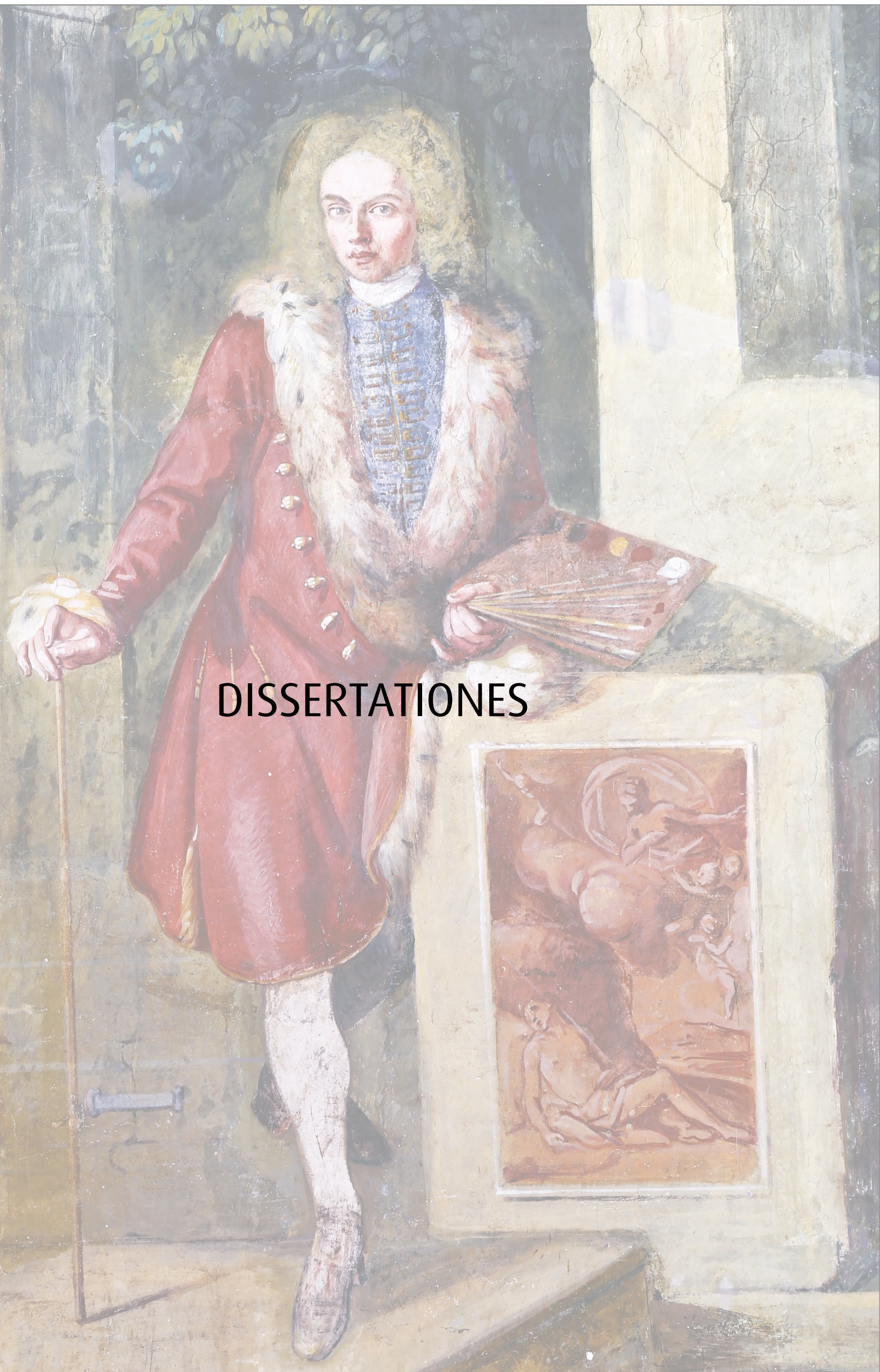




\title{
Franz Carl Remp zwischen Graz und Wien
}

\section{Georg Lechner}

Dr. Georg Lechner, Belvedere, Wien, Prinz Eugen-Straße 27, 1030 Wien, g.lechner@belvedere.at

Izvleček:

Frančišek Karel Remb med Gradcem in Dunajem

1.01 Izvirni znanstveni članek

V letih 1704/05-1710 je Frančišek Karel Remb bival v Gradcu in v službi Ignaca Marije grofa Attemsa sodeloval pri opremi novozgrajene palače Attems. Ob tem so takrat nastale oltarne slike za cerkve v Gradcu, Stainzu in Voitsbergu. Najpozneje leta 1711 se je Remb z družino preselil na Dunaj in deloval zlasti za benediktinski samostan Kremsmünster in samostan avguštinskih kanonikov St. Florian. Rembova dela za palačo Attems so stilistično heterogena. Glede na nekajletno nastajanje so razlike lahko posledica nameravane namestitve slik, predvsem pa slikarskega razvoja umetnika med izvajanjem obsežnega naročila. Med poznejšimi deli se zlasti leta 1713 dokončani cikel historičnih slik za samostan Kremsmünster odlikuje s kompozicijskim in slikarskim bogastvom. Rembovo nadaljnje slikarsko zorenje med dunajskim obdobjem potrjujejo supraporte za samostan St. Florian.

Ključne besede: Frančišek Karel Remb, baročno slikarstvo, naročništvo, Ignac Marija Attems, grad Brežice, palača Attems v Gradcu

\author{
Abstract: \\ Franz Carl Remp between Graz and Vienna
}

1.01 Original scientific article

Between 1704/1705 and 1710 Franz Carl Remp lived in Graz and while in the service of Ignaz Maria Count of Attems participated in the furnishing of the newly built Palais Attems. At the same time, he produced altar paintings for churches in Graz, Stainz, and Voitsberg. Remp and his family moved then to Vienna - 1711 at the latest - and during this time he mainly worked for the Kremsmünster Benedictine monastery and the St. Florian Augustinian Canons' monastery. Remp's works for the Palais Attems are stylistically heterogeneous. Since they were several years in the making, the differences could be a consequence of the intended placement of the paintings, and especially of Remp's artistic development during the execution of the large commission. Among his later works, the cycle of historical paintings for the Kremsmünster monastery, which was finished in 1713, is particularly recognized for the richness of its composition and painting. The sopraporte for the St. Florian's monastery attest to Remp's maturation as a painter during his Viennese period.

Keywords: Franz Carl Remp, Baroque painting, patronage, Ignaz Maria Attems, Brežice Castle, Palais Attems in Graz 
Wann genau der am 14. Oktober $1675^{1}$ in Ratmannsdorf (Radovljica) getaufte Franz Carl Remp nach Graz übersiedelte, ist nicht zu eruieren. Wie so oft bei Künstlern des Barock, lässt sich auch seine Biografie - trotz zahlreicher Quellen und Dokumente - nur lückenhaft nachzeichnen. Fest steht, dass sich der anfänglich bei seinem Vater Johann Georg Remp (1648/1650-1716) ausgebildete Maler im Jahr 1694 ,in der frembde“ befand, um seine Fertigkeiten zu vervollkommnen. Am 5. Juni desselben Jahres suchte der ältere Remp bei den Krainer Ständen um eine Förderung für seinen abwesenden Sohn an, die in einer Höhe von 150 Gulden gewährt wurde. Bis zur Feststellung dieser Tatsache galt nämlich die Annahme, dass der junge Künstler ein Stipendiat von Ignaz Maria Graf Attems (1652-1732) war. ${ }^{2} 1696$ bat Johann Georg Remp neuerlich um Unterstützung für seinen Sohn, der sich damals in Rom befand und in eine Notlage geraten war. Daraufhin erhielt er 200 Gulden zugesprochen. ${ }^{3}$ Während Rom als Aufenthaltsort damit belegt ist, können etwaige weitere Stationen vorläufig nur auf stilkritischem Weg erörtert werden.

In der 1715 von Johannes Gregor Thalnitscher (Dolničar, 1655-1719) verfassten Biografie heißt es, Remp sei nach Venedig und Rom gelangt, wo er an der Akademie studiert habe. ${ }^{4}$ Diese Behauptung lässt sich jedoch nicht verifizieren, denn im Schülerverzeichnis ist sein Name nicht nachweisbar. ${ }^{5}$

Im Ausgabenbuch der gräflich Attems'schen Herrschaft Rann (Brežice) finden sich für den Zeitraum vom 12. März 1702 bis zum 11. März 1703 Hinweise auf einen „Maller Franz“, einen „Maller Wasellio“, der wohl mit Vergoldungsarbeiten betraut worden war, sowie einen „andern Maller, so allein 14 Tag alda gewest" ${ }^{\text {" }}$ Bei den Ausgaben für Schmalz und Speck findet sich zusätzlich der Hinweis, dass sich der Maler Franz neuneinhalb Wochen in Brežice aufgehalten hat. Dies alles lässt den Schluss zu, dass es sich dabei um Franz Carl Remp handelt, der damals an der Freskierung des Festsaales im Schloss gearbeitet hat.

1707 begegnet uns Remp bereits in Graz, wo er sich gegen den Vorwurf der Frötterei verteidigen musste: Er soll unerlaubterweise auch für andere Auftraggeber als den Grafen Attems tätig gewesen sein und obendrein einen Lehrjungen unter seine Fittiche genommen haben. Letztlich erwiesen sich die Anschuldigungen als haltlos. Die Eingabe von Ignaz Maria Attems enthält die Information, dass er den Künstler bereits „vor sehr vill Jahren“ aufgenommen habe und dass er für ihn nach dessen Eheschließung ein Quartier außerhalb seines Hauses suchen musste. ${ }^{7}$ Wann

1 Publikation des Eintrags aus dem Taufbuch: Viktor STESKA, Štiri pisma župnika Franca Avsca, Zbornik za umetnostno zgodovino, 22/1-2, 1944, S. 140-141; Blaž RESMAN, O nekaterih starejših radovljiških likovnih umetnikih, Radovljiški zbornik 1995, Radovljica 1995, S. 191, Anm. 24.

2 Diese Behauptung findet sich bei Joseph WARTINGER, Aeltere plastische Künstler in Steyermark, Steyermärkische Zeitschrift, 11, 1833, S. 99, und konnte durch Uroš LUBEJ, Prispevki k biografijam na Kranjskem delujočih flamskih in holandskih slikarjev druge polovice XVII. stoletja, Acta historiae artis Slovenica, 2, 1997, S. 37, widerlegt werden. Vgl. auch Igor WEIGL, „Die Einheimischen bewundern die Gemälde“. Graf Ignaz Maria von Attems-Heiligenkreuz als Auftraggeber und Sammler, Kunsthistoriker, 18/19, 2001/2002 (2003), S. 54, Anm. 14.

3 Blaž RESMAN, „Podpisi“ svetnih naročnikov na sakralnih umetninah, Profano v sakralnem. Študije o vizualizaciji posvetnih teženj in motivov v cerkveni umetnosti (Hrsg. Mija Oter Gorenčič), Ljubljana 2019, S. 136, Anm. 17.

4 Ioannes Gregorius THALNITSCHER, Ectypon Bibliothecae Publicae Labacensis, 1715, Semeniška knjižnica, Ljubljana, rkp. 14, S. 102.

5 Freundliche Mitteilung von Angela Cipriani.

6 Steiermärkisches Landesarchiv, Graz (StLA), Archiv Attems, K. 301, H. 1743. Der Maler Franz wird auf Fol. 9r sowie auf Fol. 14r erwähnt. Dieses Dokument wurde erstmals von Igor Weigl berücksichtigt; Igor WEIGL, Matija Persky. Arhitektura in družba sredi 18. stoletja, Ljubljana 2000 (unpublizierte Magisterarbeit), S. 41, Anm. 142.

7 StLA, I. Ö. Reg., Ea., 1707-VII-56. Vollständige Abschrift in Ida SCHMITZ, Kirche und Kloster der Ursulinen in 
und wo Remp seine Frau Maria Ludovica ehelichte, entzieht sich unserer Kenntnis; in den Grazer Matriken dieser Jahre konnte zumindest bislang kein Hinweis gefunden werden. Als Trauzeuge ist Remp noch am 28. April 1710 bei der Verehelichung von Johann Anton Benedict Popill mit Maria Barbara Fellner in Graz nachweisbar. ${ }^{8}$ Am 24. Februar 1712 wurde sein Sohn Franz Joseph jedoch bereits in Wien getauft, weshalb eine Übersiedlung aus Graz in die Haupt- und Residenzstadt im Jahre 1711, vielleicht auch bereits 1710, anzunehmen ist. ${ }^{9}$ In den Jahren 1712 und 1713 findet sich Remp mehrfach in den Zahlungsbüchern des Benediktinerstiftes Kremsmünster und ab 1713 bis zu seinem Ableben im Jahr 1718 auch in jenen des Augustiner-Chorherrenstiftes St. Florian. 1715 erfolgte seine Ernennung zum kaiserlichen Titular-Hof-Historienmaler, was es ihm ermöglichte, gleichsam als Unternehmer zu agieren. ${ }^{10}$ Eine Tätigkeit für den kaiserlichen Hof respektive eine Bezahlung war damit nicht verbunden. Wie sich seine Auftragslage von da an gestaltete, lässt sich schwer eruieren, da aus dem Zeitraum zwischen 1715 und 1718 bislang nur verhältnismäßig wenige Werke bekannt sind.

Nachdem seine Frau Maria Ludovica bereits am 11. Dezember 1717 im Alter von nur 29 Jahren verstorben war, folgte ihr Franz Carl Remp am 22. September 1718 nach. Die beiden minderjährigen Töchter Maria Francisca und Maria Victoria waren nun Vollwaisen. Während sich von der ersten jegliche Spur verliert, ehelichte die zweite am 15. Februar 1729 Ignatius Schossek, der im Ehekontrakt als „Kay[serlicher] leib garde Hatschier“ erscheint. Das weitere Schicksal des Paares ist nicht bekannt. Ursprünglich hatte der Maler seinen Bruder, den Juristen Joseph Anton Remp, als Vormund seiner Töchter vorgesehen. Dieser muss jedoch bald nach Franz Carl Remp verstorben sein, weshalb schließlich der dritte Bruder, der Geistliche Ignaz Johann Remp, zum Vormund der beiden Schwestern wurde. Er war in den niederösterreichischen Orten Senning, Gastern und zuletzt in Kühnring tätig, wo er 1744 verschied. ${ }^{11}$

Einige Aufschlüsse in Bezug auf die Lebensumstände von Franz Carl Remp erlaubt das 1719 erstellte Verlassenschaftsinventar. ${ }^{12}$ Geld und Silber waren im Ausmaß von lediglich 4 Gulden und 6 Kreuzern vorhanden. Dies legt den Schluss nahe, dass der Künstler in der letzten Zeit seines Lebens seinem Beruf kaum oder gar nicht mehr nachgehen konnte und etwaige Reserven aufgebraucht waren. Ein Blick auf die vorhandenen Textilien und Möbel zeigt allerdings deutlich, dass Remp und seine Familie doch gutbürgerlich gelebt haben müssen. Unter seinen Kleidungsstücken finden sich etwa Rock, Weste und Hosen aus rotem Stoff, die mit goldenen Knöpfen und Borten bestückt waren und an eine elegante Erscheinung des Malers denken lassen - etwa vergleichbar dem freskierten Selbstbildnis in Brežice (Abb. 1). Mit Spitzen besetzte Leintücher sprechen ebenfalls für einen gediegenen Haushalt. Letzten Endes umfasste die Schätzsumme 318 Gulden und 29 Kreuzer, wovon aber allein 183 Gulden auf die hinterlassenen respektive noch nicht bezahlten

Graz. Ein Beitrag zur steiermärkischen Kunstgeschichte, Graz 1927 (unpublizierte Dissertation), S. 83-87 [recte: 86-89], Nr. 2; Georg Matthias LECHNER, Der Barockmaler Franz Carl Remp. 1675-1718, Wien 2010 (unpublizierte Dissertation), S. 207-210, Q 4.

8 Diözesanarchiv Graz, Altmatriken der Stadtpfarre Graz-Hl. Blut, Trauungsbuch VIII (1700-1714), S. 341.

9 Pfarrarchiv St. Stephan, Wien, Taufprotokoll 1711-1713, 24. Februar 1712.

10 Österreichisches Staatsarchiv (OeStA), Haus-, Hof- und Staatsarchiv (HHStA), Wien, Obersthofmeisteramt, Hofparteienprotokolle des Obersthofmeisteramtes, Bd. 8, Fol. 416r- 417r.

11 Diözesanarchiv St. Pölten, Pfarre Kühnring, Tauf-, Trauungs- und Sterbebuch, 1.1.1671-31.12.1783, Sign. 01,2,3/02, 5. November 1744. Für diesen Hinweis habe ich Brigitta Remp zu danken.

12 OeStA, HHStA, Obersthofmarschallamt, Abhandlungen, Karton 667 (Nr. 2000-2089, 1719-1729), Abhandlung 2047 (1719). Vollständige Transkription in LECHNER 2010 (Anm. 7), S. 222-225. 
Gemälde entfielen. Eingedenk der Tatsache, dass Remp in Kremsmünster pro Altarbild 300 Gulden und pro Historienbild 200 Gulden erhalten hatte, wird einem bewusst, wie gering seine Hinterlassenschaft war. Inwieweit Remp der Autor sämtlicher in seiner Wohnung befindlichen Gemälde war, muss offen bleiben, da sich keine explizite Nennung irgendeines Namens in der von dem kaiserlichen Hofmaler Nikolaus Rixner ${ }^{13}$ erstellten Schätzliste findet. Die wertvolleren unter den Werken sind ein $\mathrm{Hl}$. Franziskus in Lebensgröße um 100 Gulden, der sich beim Spitalmeister des kaiserlichen Spitals befand, ein nicht näher bezeichnetes Gemälde beim Grafen Seilern um 60 Gulden, das aber gestrichen wurde, ein ebenfalls gestrichenes Stück eines Bauern mit der Flöte um 40 Gulden bei „Reverendarij Manigetin [?]“ sowie ein Diogenes um 30 Gulden bei „hoff secretarj Siberts“. In diesen Fällen ist anzunehmen, dass es sich um Werke von Remp handelt, deren Bezahlung wohl noch ausstand. Interessant sind bei dieser

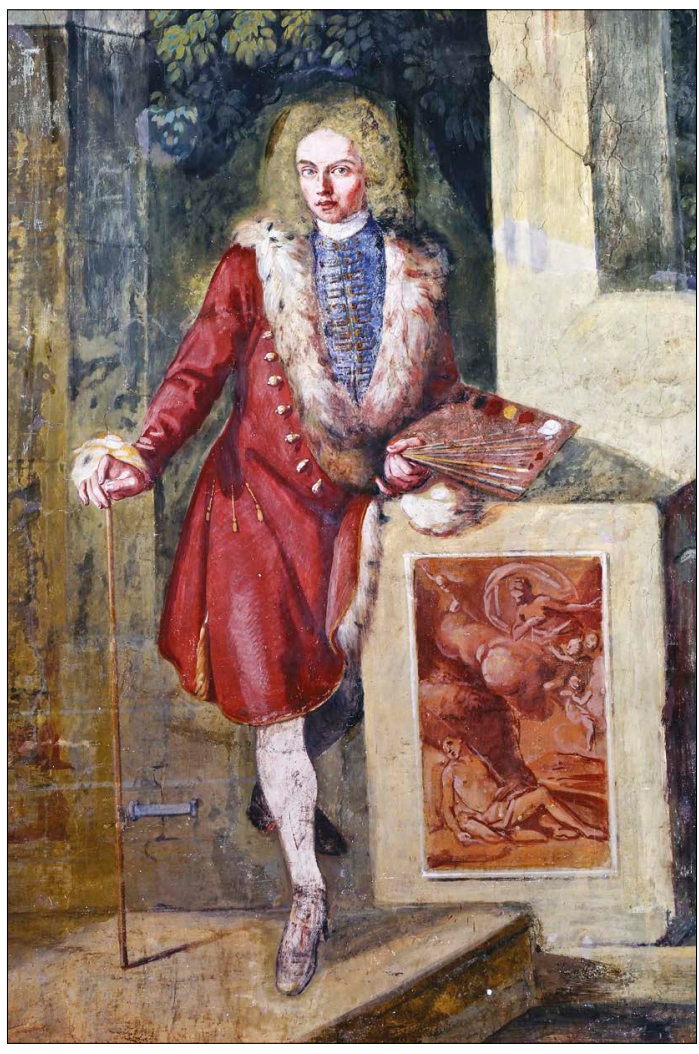

1. Franz Carl Remp: Selbstbildnis, Schloss Brežice kleinen Auswahl die unterschiedlichen Themen, wobei der Bauer mit der Flöte überrascht, da aus dem Opus des Künstlers derartige Genredarstellungen bislang nicht bekannt sind. Von der Schätzung ausgenommen wurden fünf Porträts, bei denen es sich vielleicht um Bildnisse von Familienmitgliedern handelte.

Es ist ein Zeitraum von weniger als zwei Jahrzehnten, aus denen Arbeiten von Franz Carl Remp bekannt sind. Das Schaffen reicht vom Frühwerk in Slowenien nach seiner Rückkehr aus Italien (um 1702/1703) über die Tätigkeit als Hofmaler für den Grafen Ignaz Maria Attems in Graz (wohl um 1704/1705 bis um 1711) bis hin zu den Wiener Jahren, in denen er insbesondere für die oberösterreichischen Stifte Kremsmünster (1712/1713) und St. Florian (1713 bis 1718) Aufträge ausführte. Gerade hinsichtlich der letzten Lebensjahre sind jedoch nicht besonders viele Werke bekannt, sodass hier noch mit weiteren Gemälden zu rechnen ist. Dies ist vor allem in Bezug auf private Auftraggeber interessant, die es - den Angaben in der oben genannten Schätzliste folgend - gegeben haben muss.

$\mathrm{Zu}$ den frühesten bekannten Arbeiten zählt das im Erzbischöflichen Palais in Ljubljana befindliche Herz Jesu-Bild (Abb. 2). Dieses befand sich ursprünglich in dem Konvent der Klarissen in Ljubljana, die bereits 1702 - und damit für mitteleuropäische Verhältnisse sehr früh - um ein

13 Der aus Bayern gebürtige Nikolaus Veit Rixner, dessen genaue Lebensdaten unbekannt sind, ist zwischen 1691 und 1731 in Wien durch Dokumente fassbar und fungierte mehrfach als Schätzmeister. Siehe dazu Herbert HAUPT, Das Hof- und hofbefreite Handwerk im barocken Wien 1620 bis 1770. Ein Handbuch, Wien-Innsbruck 2007 (Forschungen und Beiträge zur Wiener Stadtgeschichte, 46), S. 646, Nr. 3371. 


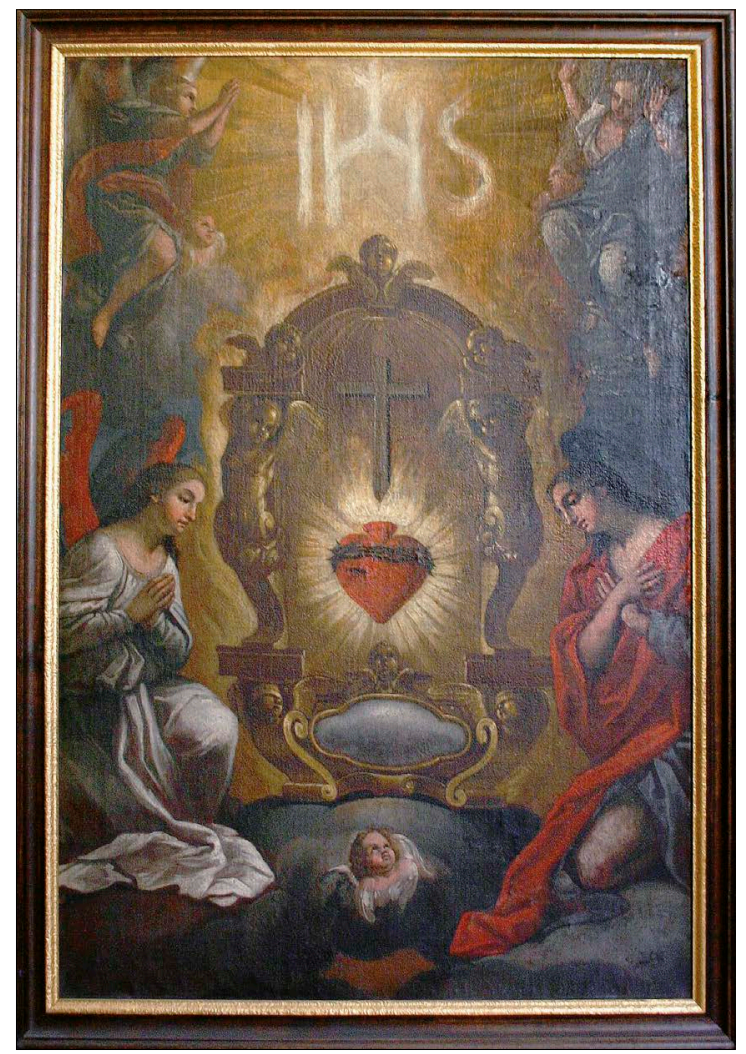

2. Franz Carl Remp: Herz Jesu-Bild, Erzbischöfliches Ordinariat, Ljubljana
Privileg zur Gründung einer Herz Jesu-Bruderschaft ansuchten. ${ }^{14}$ Die Entstehung des Gemäldes fällt damit sehr wahrscheinlich in die unmittelbare Zeit vor Remps Weggang aus seiner Heimat Richtung Graz. Im Übrigen ist die Autorschaft durch die Erwähnung in den Annales Urbis Labacensis von Johannes Gregor Thalnitscher überliefert. ${ }^{15}$

Die Komposition beruht auf der zweiten Offenbarung der hl. Margareta Maria Alacoque, die anschließend von ihr selbst oder von einer Novizin in Form einer Zeichnung dokumentiert wurde. ${ }^{16}$ Verbreitung erlangte diese Form der Darstellung vor allem durch Gebetszettel, und gewiss hat auch Franz Carl Remp für sein Gemälde auf einen solchen zurückgegriffen. Anna Coreth erwähnt etwa das Bruderschaftsblatt der Wiener Herz JesuBruderschaft, ${ }^{17}$ das jedoch nur den zentralen Teil zeigt. Weitere Beispiele dieser kleinformatigen Blätter mit Texten in französischer und in niederländischer Sprache zeigen auch die vier adorierenden Engel, sodass wir annehmen dürfen, dass diese oder weitere Remp bekannt gewesen sind. ${ }^{18}$ Und gerade durch diese Engel vermag der Künstler die bildlich festgehaltene Vision vom streng Dokumentarischen zu befreien und dem Gemälde seinen eigenen künstlerischen Stempel aufzudrücken. Der links dargestellte Engel lässt sich gut mit dem David in David bei Abimelech ${ }^{19}$ vergleichen. Dieses Werk kam 1861 als Legat von Ignaz Graf Attems in die Sammlung der Alten Galerie in Graz, fungierte einst wohl als Supraporte und wurde in

14 Anna CORETH, Liebe ohne Maß. Geschichte der Herz-Jesu-Verehrung in Österreich im 18. Jahrhundert, Maria Roggendorf 1994 (Cor ad cor. Schriften im Dienst der Herz-Jesu-Verehrung, 4), S. 33. Hinsichtlich der Ikonografie des Herz Jesu-Bildes ist die Mitwirkung der Jesuiten anzunehmen, die als Beichtväter der Klarissen agierten. Siehe dazu Blaž RESMAN, Šentjakobska cerkev v 18. stoletju, Jezuitski kolegij v Ljubljani (1597-1773). Zbornik razprav (Hrsg. Vincenc Rajšp), Ljubljana 1998 (Redovništvo na Slovenskem, 4), S. 192, sowie Ana LAVRIČ, Bratovščine v klariških samostanih na Kranjskem. Njihova umetnostna in duhovna dediščina, Acta historiae artis Slovenica, 25/1, 2020, S. 31-33.

15 Ioannes Gregorius THALNITSCHER, Annales Urbis Labacensis. Das ist Laybacherische Jahrsgeschichten Von An[no] 1660, bis 1700. Continuiert von an[no] 1700 bis 1718, Semeniška knjižnica, Ljubljana, rkp. 11, Fol. 130v.

16 Heilige Margareta Maria Alacoque. Leben und Offenbarungen von ihr selbst geschrieben und ergänzt durch Zeitgenossen, Freiburg 1984³, S. 77-78, 194-195.

17 CORETH 1994 (Anm. 14), S. 65.

18 Vgl. Antiquariat Bierl, Eurasburg, Katalog 183, Winter 2020, S. 96, Nrn. 960, 962, 963 (letztere mit Abb.).

19 Graz, Universalmuseum Joanneum, Alte Galerie, Inv. Nr. 180, Öl auf Leinwand, $94 \times 188,5 \mathrm{~cm}$. 
der älteren Literatur hinsichtlich der Zuschreibung angezweifelt. ${ }^{20}$ Gerade die Gegenüberstellung zeigt jedoch, dass es sich um denselben Künstler handeln muss, wobei das Grazer Bild wohl bald darauf entstanden sein dürfte.

Gleichsam den Übergang zur Grazer Zeit markiert die Freskierung des Festsaales in Brežice. Auch wenn Franz Carl Remp immer wieder in Zusammenhang mit den Fresken genannt wurde, galt die Frage der Zuschreibung lange Zeit als ungeklärt. So wurde etwa die Zusammenarbeit von zwei verschiedenen Künstlern erwogen. ${ }^{21}$ Mittlerweile herrscht Konsens darüber, dass es sich dabei um ein Werk von Remp handelt. Die erfolgreiche Ausgestaltung dieses Saales auf einem Landschloss war gewiss eine gute Empfehlung für den umfangreichen Auftrag der künstlerischen Ausstattung des Grazer Stadtpalais als zukünftigem Hauptsitz der gräflichen Familie Attems.

Die nicht zu leugnende stilistische Heterogenität in Brežice scheint sich jedoch dadurch zu erklären, dass ein junger Künstler, der mit vielfältigen Eindrücken von einer Studienreise zurückgekehrt ist, einen großen Auftrag erhält, der seine Selbstständigkeit enorm herausfordert. So kommt es nicht zu einer ineinander verwobenen illusionistischen Deckengestaltung, sondern zu einem Aneinanderfügen von Einzelszenen. Noch später, in den Fresken des Palais Attems, die im Format freilich kleiner sind, macht sich diese Eigenschaft bemerkbar. Remp blieb - anders als etwa Johann Michael Rottmayr (1654-1730) oder später Daniel Gran (1694-1757) - zeitlebens dem klassischen Staffeleigemälde verpflichtet und fand sich in derart großen Maßstäben nur mühevoll zurecht. Auch die Deckengemälde des Palais Attems scheinen mehrheitlich als konventionelle Staffeleibilder gedacht, die den Raum nach oben hin kaum bis gar nicht öffnen und ebenso für eine Präsentation an der Wand geeignet wären. Dies betrifft insbesondere Darstellungen wie Achilles und Cygnus, Luna und Endymion und das Urteil des Paris in den hinteren drei Räumen des ersten Stockwerks sowie die durchaus bravouröse Umsetzung von Jakob und Rahel am Brunnen im ersten Raum des zweiten Stocks.

Ganz anders muten hingegen die sechs hochovalen Gemälde an, die ursprünglich sämtlich Teil der Wandgestaltung des Saales in Brežice waren und bei denen es sich um vier allegorische Darstellungen sowie zwei Familienbildnisse handelt. ${ }^{22}$ Drei Allegorien befinden sich nach wie vor in situ, die vierte konnte durch die Narodna galerija in Ljubljana erworben werden. Lange Zeit als verschollen galten zwei Gemälde, von denen eines Ignaz Maria Graf Attems mit dreien seiner Söhne zeigt und das andere seine erste Gemahlin Maria Regina (1659-1715), geborene Freiin von Wurmbrand-Stuppach, mit der Tochter Maria Charlotte sowie zwei weiteren kleinen Knaben.

20 Robert Meeraus spricht knapp von einem „angeblichen Remp“, und Ida Schmitz reiht das Werk unter die Gemälde mit zweifelhafter Zuschreibung; Robert MEERAUS, Zur Barockausstellung im Landesmuseum „Joanneum“ in Graz, Der Cicerone. Halbmonatsschrift für Künstler, Kunstfreunde und Sammler, 16, 1924, S. 415-416; SCHMITZ 1927 (Anm. 7), S. 63 [recte: 64], Nr. 5.

${ }^{21}$ Anica Cevc erkannte stilistische Charakteristika von Matthias von Görz und stellte deshalb die alleinige Autorschaft Remps in Frage (Anica CEVC, Freske Matthiasa von Görza v Marijini cerkev v Zagorju pri Podčetrtku, Zbornik za umetnostno zgodovino, n. F. 16, 1980, S. 69, 73). Barbara Murovec wiederum vermutete, dass die Fresken von Antonio Maderni begonnen und nach dessen Tod von Franz Carl Remp vollendet wurden (Barbara MUROVEC, Antonio Maderni. Je bil pozabljeni Weissenkircherjev zet iz Capolaga prvi Attemsov freskant?, Slovenska umetnost in njen evropski kontekst (Hrsg. Barbara Murovec), Ljubljana 2007, S. 120, 122).

${ }^{22}$ Vgl. dazu in jüngerer Zeit Ferdinand ŠERBELJ, Ovalne slike Frančiška Karla Remba v Viteški dvorani brežiškega gradu, Litterae pictae. Scripta varia in honorem Nataša Golob septuagesimum annum feliciter complentis (Hrsg. Tine Germ, Nataša Kavčič), Ljubljana 2017, S. 379-393, sowie Barbara MUROVEC, Historizirana podoba naročnika. Attemsova družinska portreta in Rembov avtoportret iz brežiškega gradu, Acta historiae artis Slovenica, 23/1, 2018, S. 113-131. 


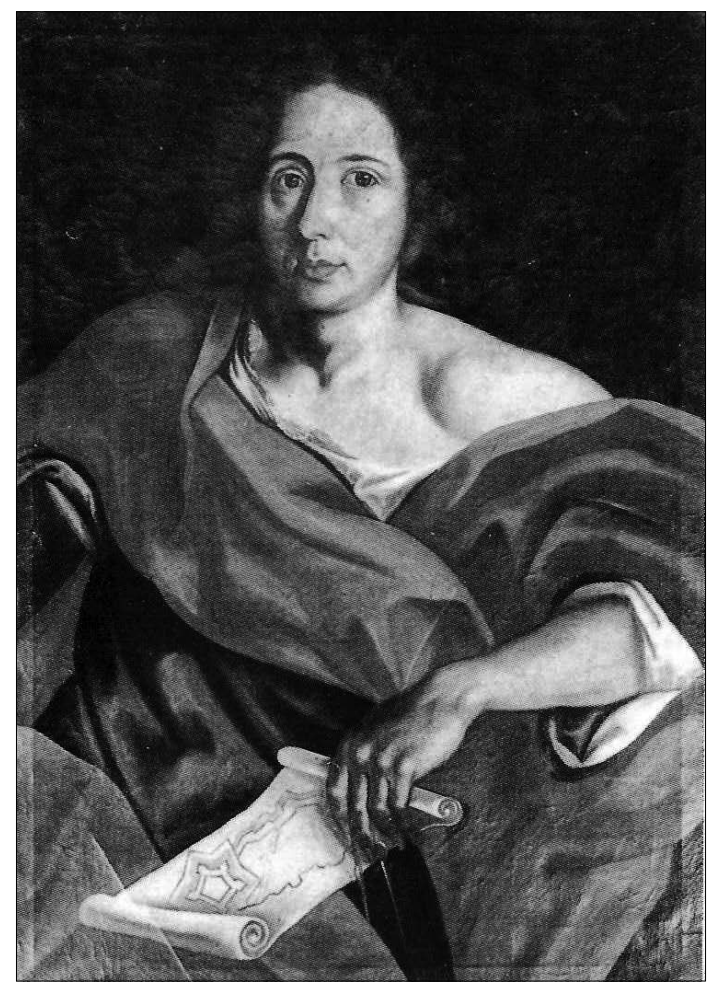

3. Franz Carl Remp (?): Ignaz Maria Graf Attems, unbekannter Verbleib
Diese beiden Bildnisse tauchten vor einigen Jahren in fragmentiertem Zustand in Privatbesitz auf und konnten auf Basis der von Ferdinand Šerbelj publizierten historischen Fotografien identifiziert werden. Mittlerweile sind sie Teil der Sammlung Schloss Eggenberg in Graz. ${ }^{23}$

Von dem Porträt des Grafen Attems existiert darüber hinaus eine Detailwiederholung, die $1994 \mathrm{im}$ Dorotheum in Wien angeboten wurde und deren Verbleib bislang ungeklärt bleiben muss (Abb. 3). ${ }^{24}$ In Unkenntnis des Originals und auf Basis der Schwarzweißabbildung ist die Autorschaft nicht definitiv zu klären, doch bezeichnend ist, dass das Gemälde im Katalog als Bildnis eines Architekten aufscheint, das von einem italienischen Künstler des 18. Jahrhunderts geschaffen wurde. Dies ist wohl durch die Ausschnitthaftigkeit bedingt, lässt aber auch den Schluss zu, dass noch weitere Gemälde Remps, deren eigentlicher Autor längst in Vergessenheit geraten ist, als Werke der italienischen Schule kategorisiert wurden.

Die von Remp für das Palais Attems in der Grazer Sackstraße geschaffenen Werke sind zahlreich und vielfältig. Sie reichen von Fres-

ken über großformatige Decken- und Historiengemälde sowie Supraporten bis hin zu Bildern, die nicht Teil der Ausstattung waren, sondern von vornherein in die Gemäldesammlung aufgenommen wurden. Ein beträchtlicher Teil davon befindet sich noch heute in situ im Palais, doch darf dies nicht darüber hinwegtäuschen, dass viele Werke veräußert wurden und sich mittlerweile zumeist in musealem Besitz befinden. Derzeit existieren noch 14 Supraportengemälde im ersten Stockwerk, während es im zweiten keine mehr gibt. Im Fideikommissinventar von 1879 sind jedoch noch 35 derartige Bilder für das gesamte Gebäude angeführt. ${ }^{25}$ In einigen Fällen gibt es zwar keinen Hinweis auf den Künstler, jedoch darf Remp zumindest in den meisten Fällen als Autor angenommen werden.

Prägend für das Erscheinungsbild der Innenausstattung des Palais müssen auf jeden Fall die großformatigen historischen und allegorischen Darstellungen gewesen sein, die in dem 1733 erstellten Verlassenschaftsinventar nach Ignaz Maria Attems in den Vorsälen des ersten und zweiten Stockwerks als "grosse ovidische Stuckh “ und „grosse St[ücke]“ angeführt sind. ${ }^{26}$ Einige dieser Gemälde sind in der Alten Galerie am Universalmuseum Joanneum erhalten. Sie weisen jeweils eine

23 Ferdinand ŠERBELJ, Bistriški grad, Slovenska Bistrica 2005, S. 52-53.

24 Alte Meister. Kunstauktion im Palais Dorotheum, Dienstag, 1. März, Wien 1994, Lot 199.

25 Archiv der Alten Galerie am Universalmuseum Joanneum, Graz, Fideikommissinventar der gräflich Attems'schen Gemäldesammlung, 1. April 1879.

26 StLA, Archiv Attems, K. 8, H. 59, Fol. 45r (publiziert in LECHNER 2010 (Anm. 7), S. 234). 


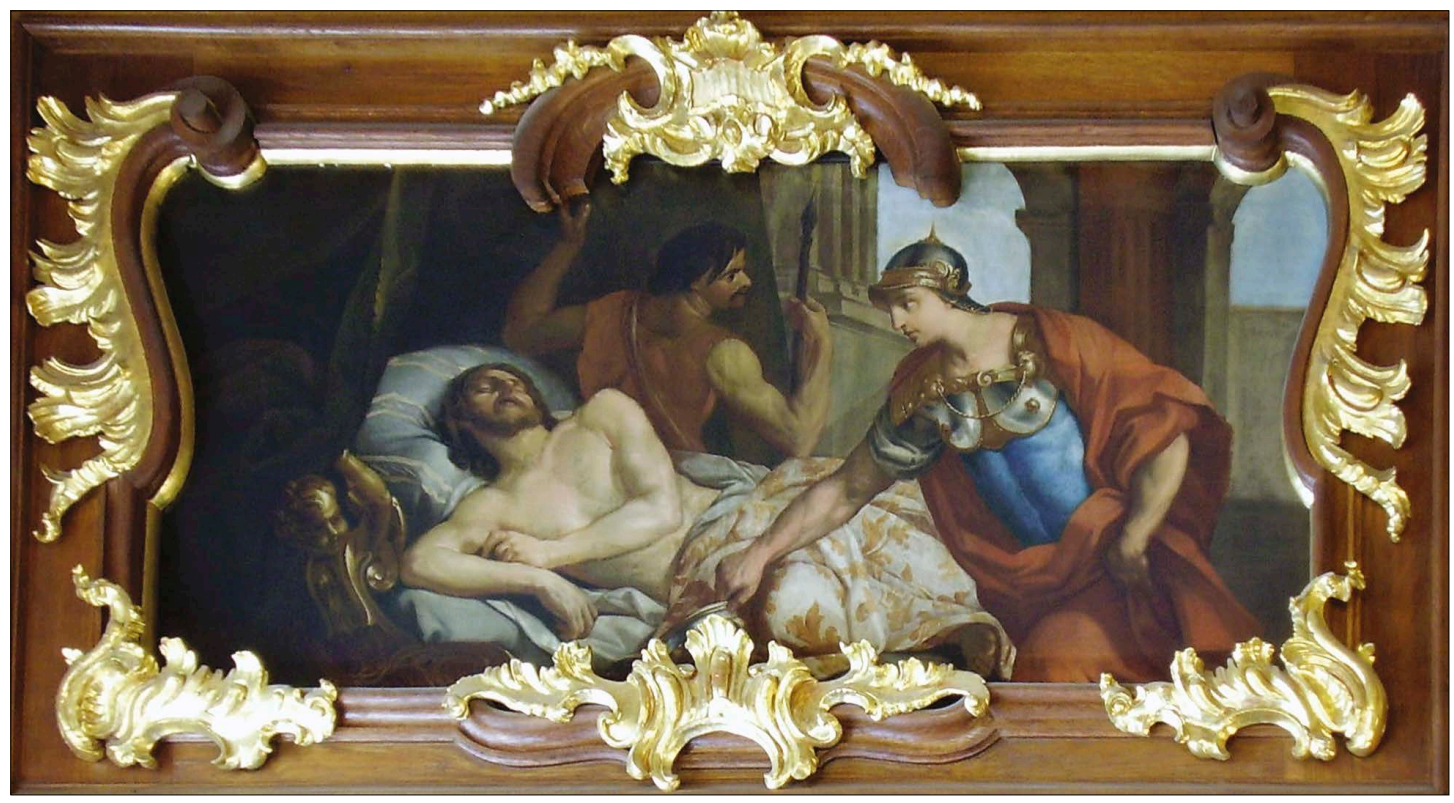

4. Franz Carl Remp: David und Abischai im Zelt des schlafenden Saul, Palais Attems, Graz

Höhe von ca. $225 \mathrm{~cm}$ bei Breiten von $308 \mathrm{~cm}$ bis $411 \mathrm{~cm}$ auf. ${ }^{27}$ Eingedenk der Dominanz derartig großer Bilder präsentieren sich beide Räume heute umso kahler und die Deckenfresken stehen in starkem Kontrast zu den einheitlich hellen Wänden.

Bei der Gegenüberstellung von Werken, die sich im Palais Attems befinden oder dafür geschaffen wurden, ergibt sich in stilistischer Hinsicht bisweilen ein heterogenes Bild. Diese Tatsache wurde in den entsprechenden Bänden des Dehio wie der Kunsttopographie mit der Hinzuziehung von Gehilfen begründet. ${ }^{28}$ Dass Remp einen derartigen Mitarbeiter hinzugezogen hat, ist aufgrund des oben erwähnten, unbegründeten Vorwurfs der Frötterei unwahrscheinlich. Daher scheint es zielführend, eine kontinuierliche Entwicklung anzunehmen und eine zumindest vage Abfolge zu definieren. Darüber hinaus ist zu berücksichtigen, dass nicht alle Werke mit derselben Konzentration ausgeführt wurden, da sie an verschiedenen Orten eingesetzt wurden und der Ausführungsgrad daher als funktionsabhängig beschrieben werden kann. Die drei Supraportengemälde im Prunkzimmer des ersten Stockwerks werden etwa in beiden Publikationen als Arbeiten von Gehilfen angeführt. Sie weisen jedoch sämtlich Charakteristika auf, die für Remps Schaffen kennzeichnend sind. Anzuführen ist dahingehend die schmale Raumbühne, in der die dargestellten Personen agieren, sowie die Integration von Köpfen im Profil. Dies zeigt etwa die Darstellung von David und Abischai im Zelt des schlafenden Saul (Abb. 4). Was auf den ersten Blick etwas sperrig anmutet, entpuppt sich bei näherer Betrachtung als präzise ausgearbeitetes Gemälde. Dies betrifft die Modellierung der Gesichter und Körper ebenso wie die detailliert wiedergegebene Bettwäsche. Es bestehen darin nicht nur Gemeinsamkeiten

27 Graz, Universalmuseum Joanneum, Alte Galerie, Inv. Nr. 1053 (Allegorie - Tapferkeit, Gerechtigkeit und Ehre), Reg. Nr. 37a (Saturn mit drei weiblichen allegorischen Figuren), Reg. Nr. 38a (Allegorie mit Saturn), Reg. Nr. 37b (Allegorie der Unschuld), Reg. Nr. 38b (Allegorie - Ein Mann, zwei weibliche Figuren und ein Genius).

28 Graz (Bearb. Horst Schweigert), Horn-Wien 1979 (Dehio-Handbuch. Die Kunstdenkmäler Österreichs), S. 9799; Die Kunstdenkmäler der Stadt Graz. Die Profanbauten des I. Bezirkes. Altstadt (Bearb. Wiltraud Resch), Graz 1996 (Österreichische Kunsttopographie, 53), S. 508-511. 


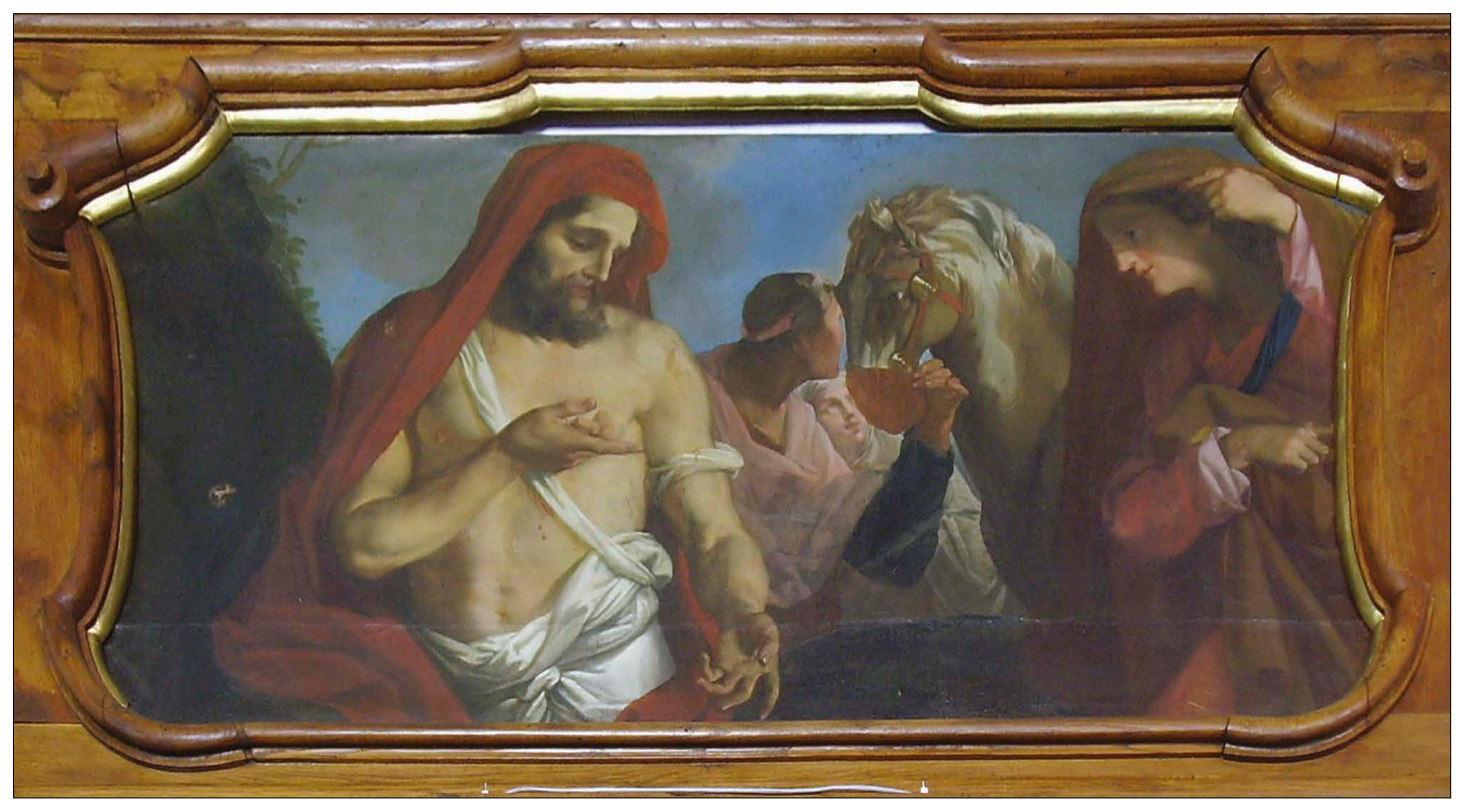

5. Franz Carl Remp: Szene aus dem Alten Testament (?), Palais Attems, Graz

mit weiteren Supraporten im Palais Attems, bei denen Remps Autorschaft bislang nicht angezweifelt wurde, sondern auch zu späteren Werken des Künstlers. Hinzuweisen ist an dieser Stelle etwa auf den Zyklus von Historiengemälden für das Stift Kremsmünster, der 1712 beauftragt und 1713 bezahlt wurde. ${ }^{29}$ Besonders in Bezug auf die Stofflichkeit wird hier ein großer Reichtum geboten, sodass umso mehr zu bedauern ist, dass von den ursprünglich dreizehn Gemälden fünf, die separat von den anderen aufbewahrt wurden, bei einem Brand im Jahr 1866 zerstört wurden. ${ }^{30}$

Angesichts des Zeitraums von mehreren - möglicherweise sechs bis acht - Jahren sind die stilistischen Unterschiede jedenfalls auch als Entwicklung zu lesen. Gerade hinsichtlich der Supraportengemälde für das Palais Attems lässt sich eine stetig größer werdende Räumlichkeit beobachten, wobei Remp das in diesem Kontext hervorstechende Porträt im strengen Profil (Abb. 5) auch in späteren Werken beibehält. Die Heterogenität der Ausführung der Gemälde ist wohl, wie bereits erwähnt, auch dadurch begründet, dass die einzelnen je nach Verwendungszweck mit unterschiedlicher Sorgfalt ausgeführt wurden.

Die Büßende hl. Magdalena (Abb. 6) sowie einige Supraportengemälde erscheinen besonders elaboriert und sind vermutlich eher gegen Ende der Grazer Zeit - also um 1710 - entstanden. Als Beispiele seien an dieser Stelle etwa Pan und Syrinx ${ }^{31}$ in Ljubljana sowie Lot und seine Töchter ${ }^{32}$

29 Archivalische Vorarbeiten zur Österreichischen Kunsttopographie. Gerichtsbezirk und Stift Kremsmünster (Hrsg. Willibrord Neumüller), 1, Wien 1961, S. 69-70, Nr. 2969.

30 P. Theophil DORN, Abriß der Baugeschichte Kremsmünsters, Heimatgaue. Zeitschrift für oberösterreichische Geschichte, Landes- und Volkskunde, 4, 1929, S. 225; Die Kunstdenkmäler des Benediktinerstiftes Kremsmünster. 1: Das Stift - Der Bau und seine Einrichtung (Bearb. Erika Doberer), Wien 1977 (Österreichische Kunsttopographie, 43), S. 439.

31 Ljubljana, Narodna galerija, Inv. Nr. ZD S 1965001, Öl auf Leinwand, 91,8 × 205 cm (Leihgabe des Spa von Rogaška Slatina).

32 Graz, Universalmuseum Joanneum, Alte Galerie, Inv. Nr. 1050, Öl auf Leinwand, $148 \times 195,5 \mathrm{~cm}$. 


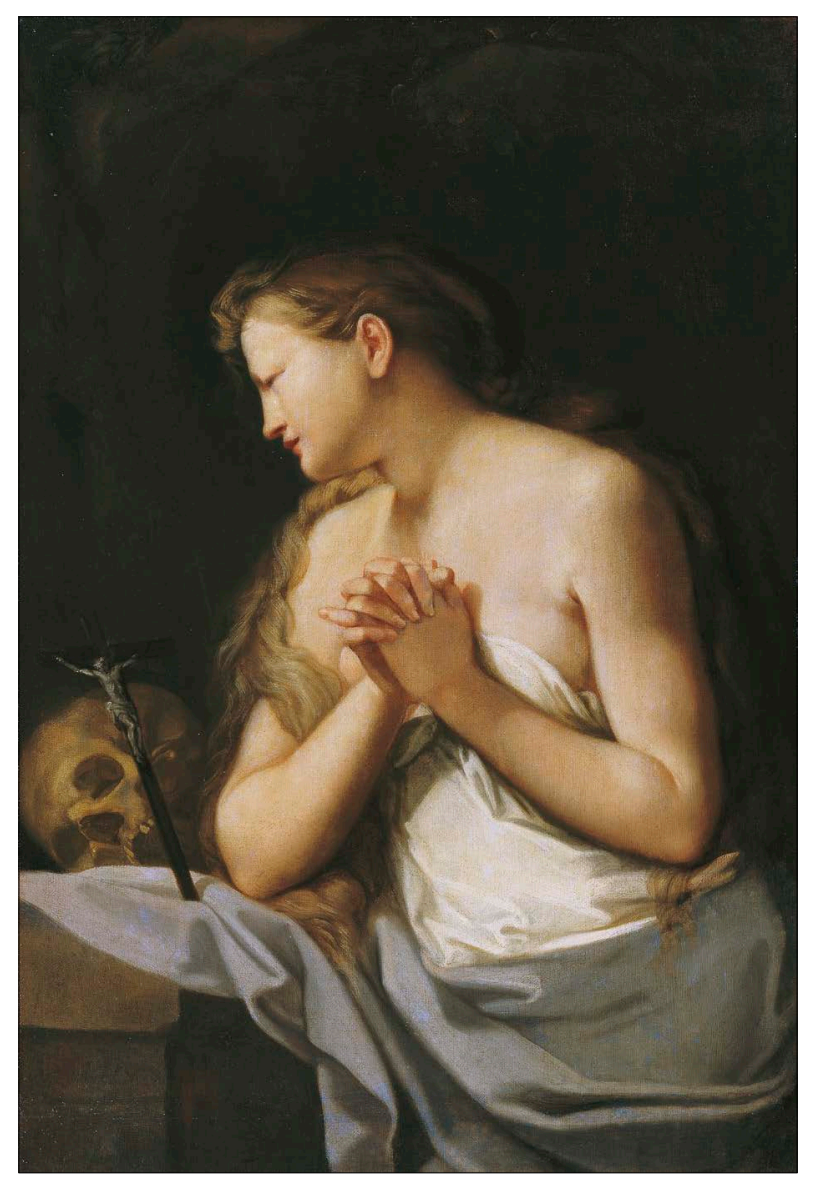

6. Franz Carl Remp: Büßende hl. Magdalena, Belvedere, Wien

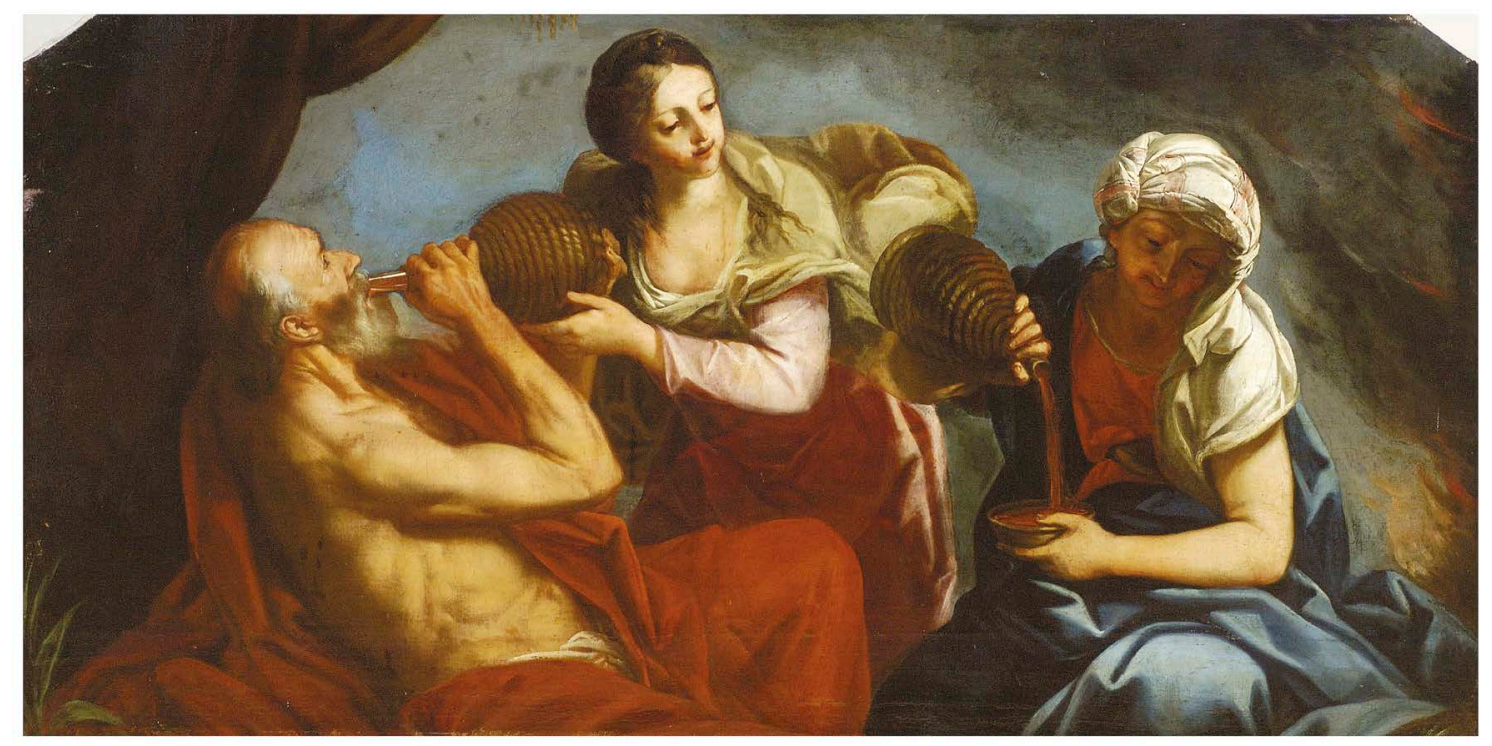

7. Franz Carl Remp: Lot und seine Töchter, Alte Galerie, Universalmuseum Joanneum, Graz 


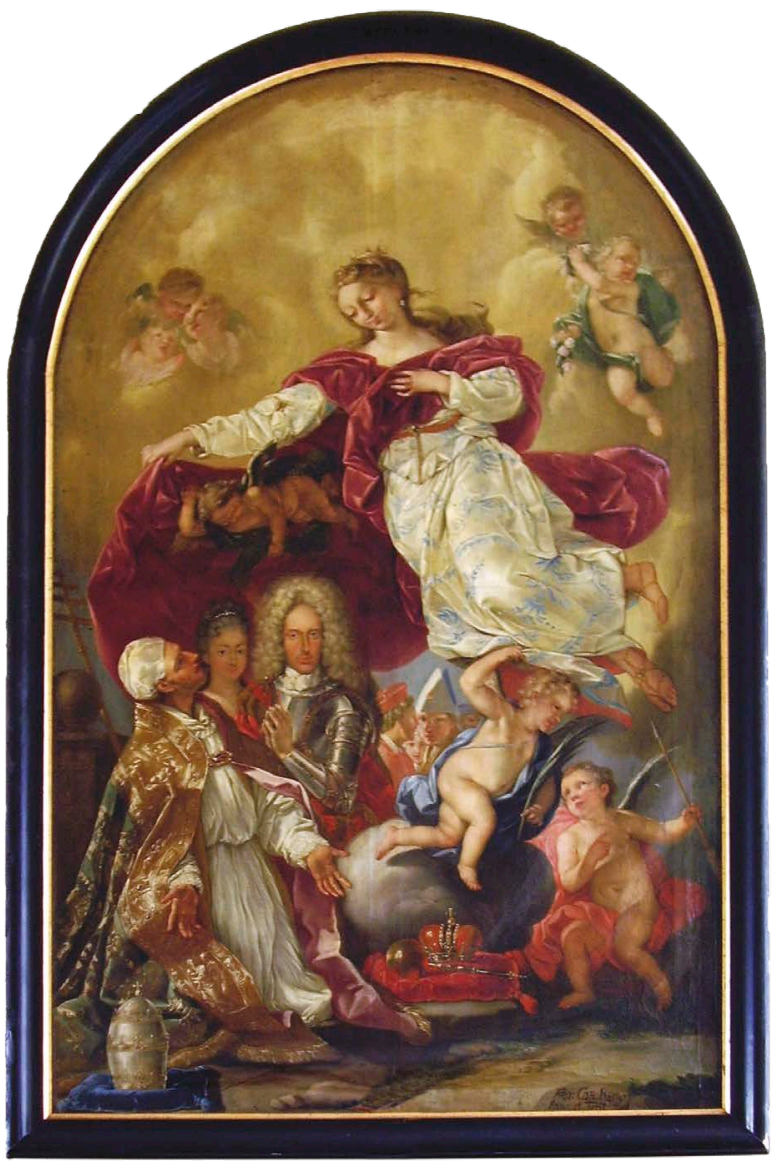

8. Franz Carl Remp: Schutzmantelbild der hl. Ursula, Ursulinenkonvent, Graz
(Abb. 7) in Graz genannt. Bei letzterem ist es vor allem die Figur Lots, die sich durch die gekonnte und sensible Modellierung sowie ein stark individualisiertes Haupt auszeichnet, während die Töchter im Vergleich eher idealisiert erscheinen.

Einen hohen Grad an Individualisierung weist auch die Büßende hl. Magdalena (Abb. 6) auf, sodass sich die Frage aufdrängt, ob Remp hier ein konkretes Modell in der Rolle einer Heiligen dargestellt hat. Auch dem Grafen Attems lag offensichtlich sehr an diesem Werk, denn es scheint im Verlassenschaftsinventar von 1733 nicht etwa in der Galerie oder in einem anderen Repräsentationsraum auf, sondern im "Grafen Zimmer", wo sich der Hausherr mit - zuzüglich der drei Supraporten - 32 Gemälden umgab. ${ }^{33}$ In Bezug auf Komposition und Bildausschnitt vergleichbare Bilder finden sich in den CEuvres der Schüler von Johann Carl Loth (1632-1698). Diese sind in der Malweise jedoch sehr unterschiedlich, wenn wir etwa an Hans Adam Weissenkircher (1646-1695) denken, dessen Stil Remp durch seinen mehrjährigen Aufenthalt in Graz vertraut gewesen sein

muss. Die präzisere, weitaus weniger großzügige Malweise erinnert eher an andere Regionen Italiens, wobei etwa auf die römische Malerei um 1700 in der Prägung von Francesco Trevisani (16561746) hinzuweisen ist. Diese Feststellung geht mit der oben angeführten Behauptung Thalnitschers einher, dass Remp sowohl in Venedig als auch in Rom gewesen sei. ${ }^{34}$

In die Grazer Zeit des Künstlers sind bislang fünf Werke zu datieren, die nicht im Zusammenhang mit dem Palais Attems stehen. Das Seitenaltarbild mit dem Martyrium der hl. Ursula in der ehemaligen Ursulinen- und nunmehrigen Dreifaltigkeitskirche in der Sackstraße wie auch das im Grazer Ursulinenkonvent befindliche Schutzmantelbild der hl. Ursula (Abb. 8) waren wohl Stiftungen von Ignaz Maria Graf Attems an die damals benachbarte Ordensgemeinschaft. Letzteres mutet hinsichtlich der Ikonografie keineswegs alltäglich an, findet aber in Slowenien wie auch in der Steiermark Vorläufer respektive Parallelen. ${ }^{35}$ Unter den Schutz der Heiligen werden hier Papst

33 StLA, Archiv Attems, K. 8, H. 59, Fol. 37v-38v. Die Magdalena von Remp scheint unter Nr. 20 auf Fol. 38v auf.

34 Zu Remps stilistischer Abhängigkeit von der italienischen Malerei über das Beispiel der Büßenden hl. Magdalena hinausgehend vgl. LECHNER 2010 (Anm. 7), S. 97-101.

35 Für den Hinweis auf das Schutzmantelbild der hl. Ursula in der Dorfkirche von Prepolje und auf das Schutzmantelbild der hl. Elisabeth bei den Elisabethinen in Graz habe ich Polona Vidmar herzlich zu danken; siehe auch 


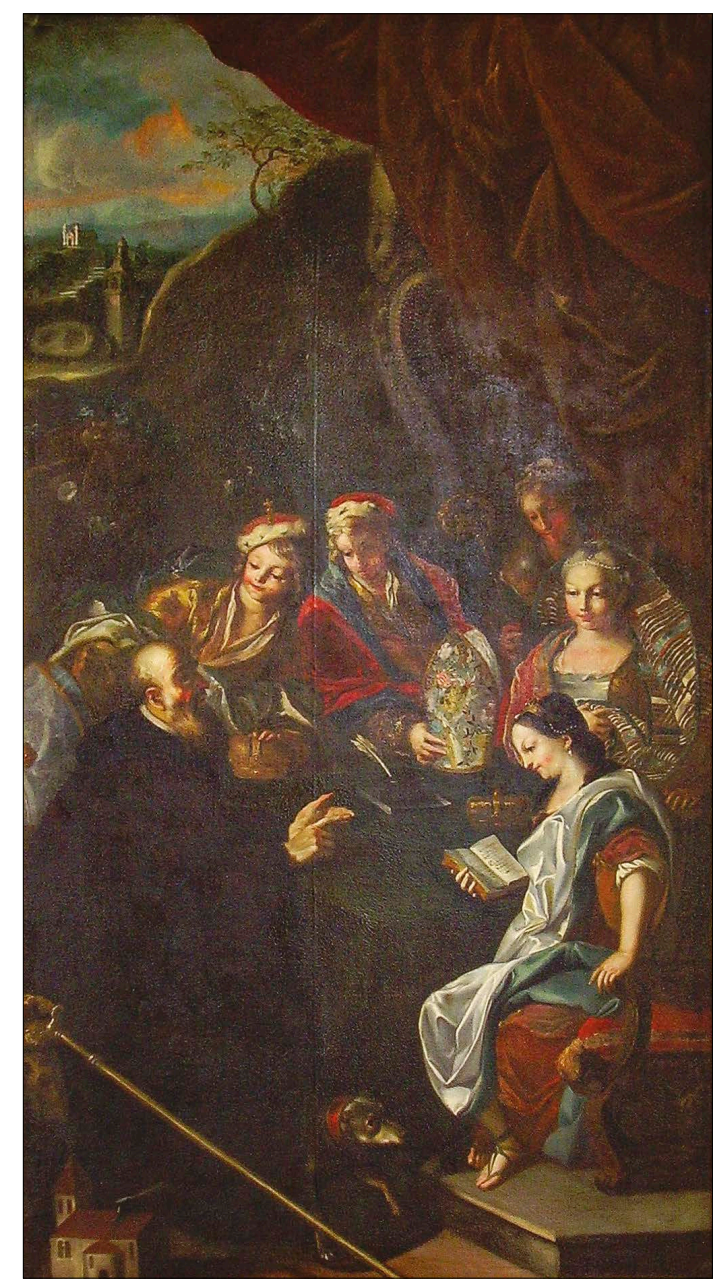

9. Franz Carl Remp: Der hl. Wolfgang unterrichtet die Kinder des Herzogs Heinrich von Bayern, Pfarrkirche, Pfarrkirchen bei Bad Hall

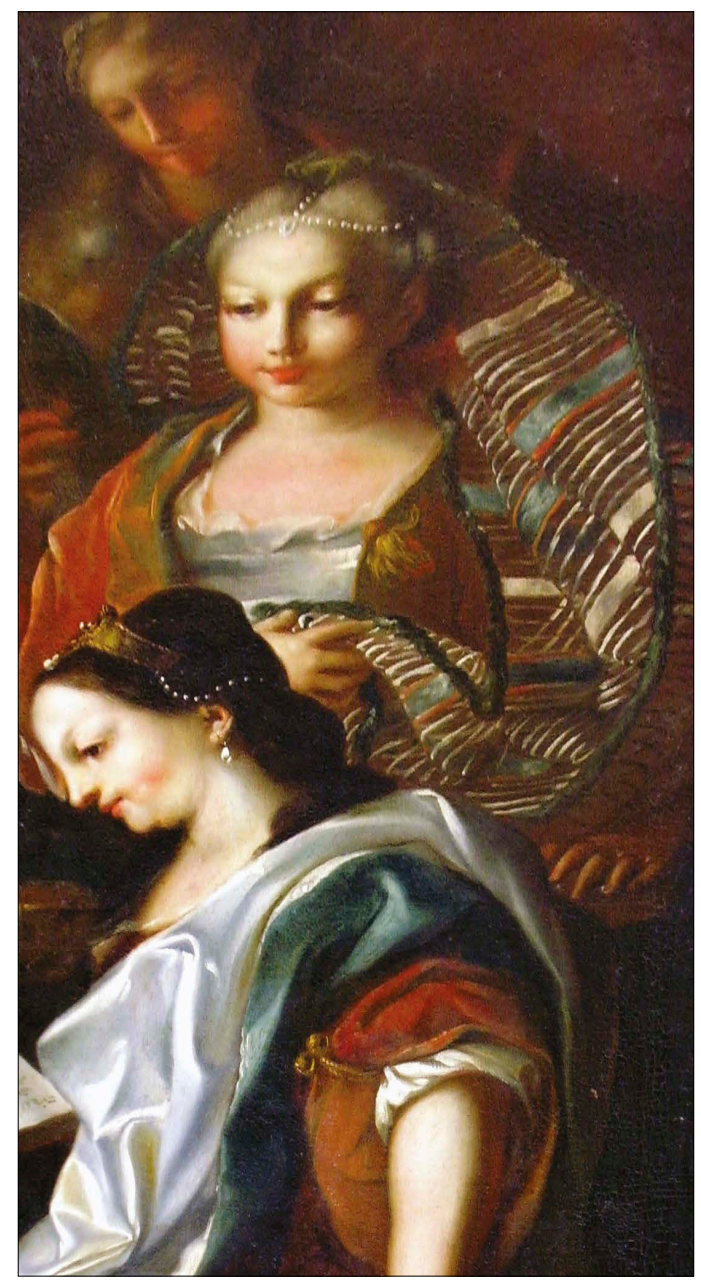

10. Franz Carl Remp: Der hl. Wolfgang unterrichtet die Kinder des Herzogs Heinrich von Bayern, Detail, Pfarrkirche, Pfarrkirchen bei Bad Hall

Clemens XI. (1649-1721, reg. ab 1700) sowie Kaiser Joseph I. (1678-1711, reg. ab 1705) gestellt. Zwischen den beiden Herrschern befindet sich das Porträt einer Dame, wobei Vergleiche mit Gemälden und Druckgrafiken nahelegen, dass es sich dabei um die Gemahlin von Joseph I., Wilhelmine Amalie von Braunschweig-Lüneburg (1673-1742), handelt. Es hat jedenfalls den Anschein, dass sie ursprünglich in der Komposition nicht vorgesehen war und erst im Lauf der Ausführung hinzugefügt wurde. Bedingt durch das Ableben des Kaisers ist jedenfalls von einer Entstehung des Gemäldes spätestens im Jahr 1711 auszugehen. Im Vergleich mit dem Altarbild des Martyriums der hl. Ursula zeigt sich, dass die beiden Werke etwa zur gleichen Zeit entstanden sein müssen.

Polona VIDMAR, / .../ weilen es in der Welt was Seltsames sei bei dieser Zeit eine andächtige Seel zu finden, die ein Kloster stiften wollte /.../. Marija Terezija grofica Leslie in ustanovitev samostana elizabetink v Gradcu, Profano v sakralnem. Študije o vizualizaciji posvetnih teženj in motivov v cerkveni umetnosti (Hrsg. Mija Oter Gorenčič), Ljubljana 2019, S. 204-206. 

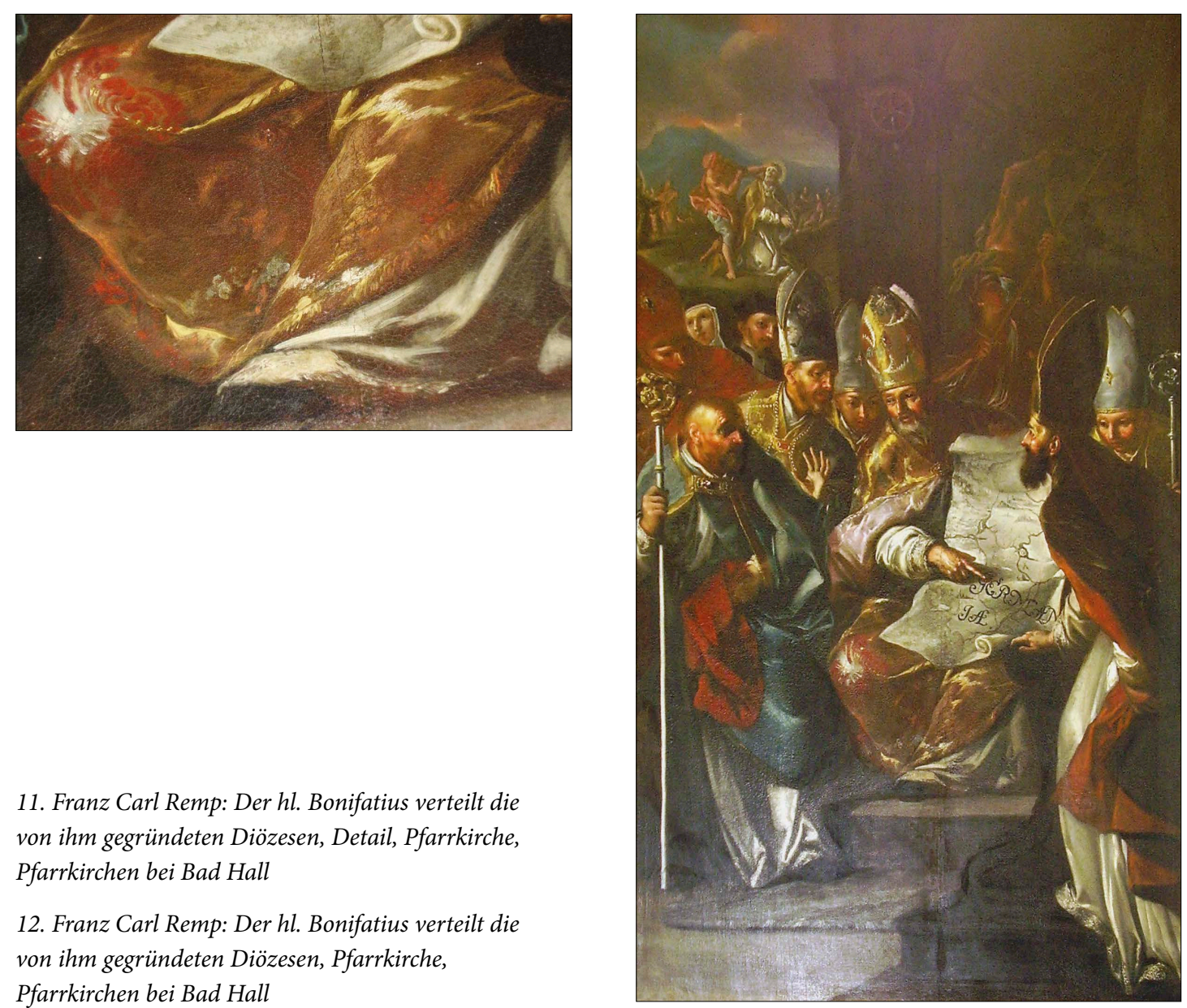

11. Franz Carl Remp: Der hl. Bonifatius verteilt die von ihm gegründeten Diözesen, Detail, Pfarrkirche, Pfarrkirchen bei Bad Hall

12. Franz Carl Remp: Der hl. Bonifatius verteilt die von ihm gegründeten Diözesen, Pfarrkirche, Pfarrkirchen bei Bad Hall

Das Hochaltarbild in der Welschen Kirche am Griesplatz in Graz, welches den Hl. Franz von Paola zeigt, dürfte ebenso in Verbindung mit dem Grafen Attems zu bringen sein. Dieser war nämlich viele Jahre lang Protektor der Bruderschaft italienischer Handwerker, die dort beheimatet war. ${ }^{36}$ Nicht aufzulösen ist hingegen die Verbindung zur heutigen Pfarr- und früheren Karmeliterkirche in Voitsberg, wo das Hochaltarbild mit dem Tod des hl. Joseph die Signatur Remps trägt, sowie zum ehemaligen Augustiner-Chorherrenstift in Stainz, wo das rechte Seitenaltarbild mit dem Hl. Augustinus Remp zuzuschreiben ist. Stilistisch ist letzteres zwischen das Schutzmantelbild der hl. Ursula und dem Hl. Franz von Paola einzuordnen.

Eine deutliche Weiterentwicklung gegenüber diesen Gemälden zeigt Der hl. Papst und Märtyrer Alexander aus dem Jahr 1712 im Benediktinerstift Kremsmünster. Neben diesem Werk sowie zwei Seitenaltarbildern für die Stiftskirche - Christus am Kreuz sowie den Tod des hl. Benedikt darstellend - schuf Remp für Kremsmünster insbesondere den bereits erwähnten Zyklus von 13 Historiengemälden. Diese umfassen Darstellungen zur Gründung des Stifts wie auch zu wichtigen Heiligen im größeren Einzugsgebiet des Stifts. Zum Zeitpunkt, als Remp diesen Zyklus schuf, blickte diese monastische Institution bereits auf eine mehr als 930 Jahre alte Geschichte zurück, wurde sie doch im Jahre 777 durch den bayerischen Herzog Tassilo III. ins Leben gerufen.

\footnotetext{
36 Karl MOSER, Die Welsche Kirche in Graz, Wien-Graz-Leipzig 1928 (Kunstdenkmäler der Steiermark, 1), S. 1-2.
} 


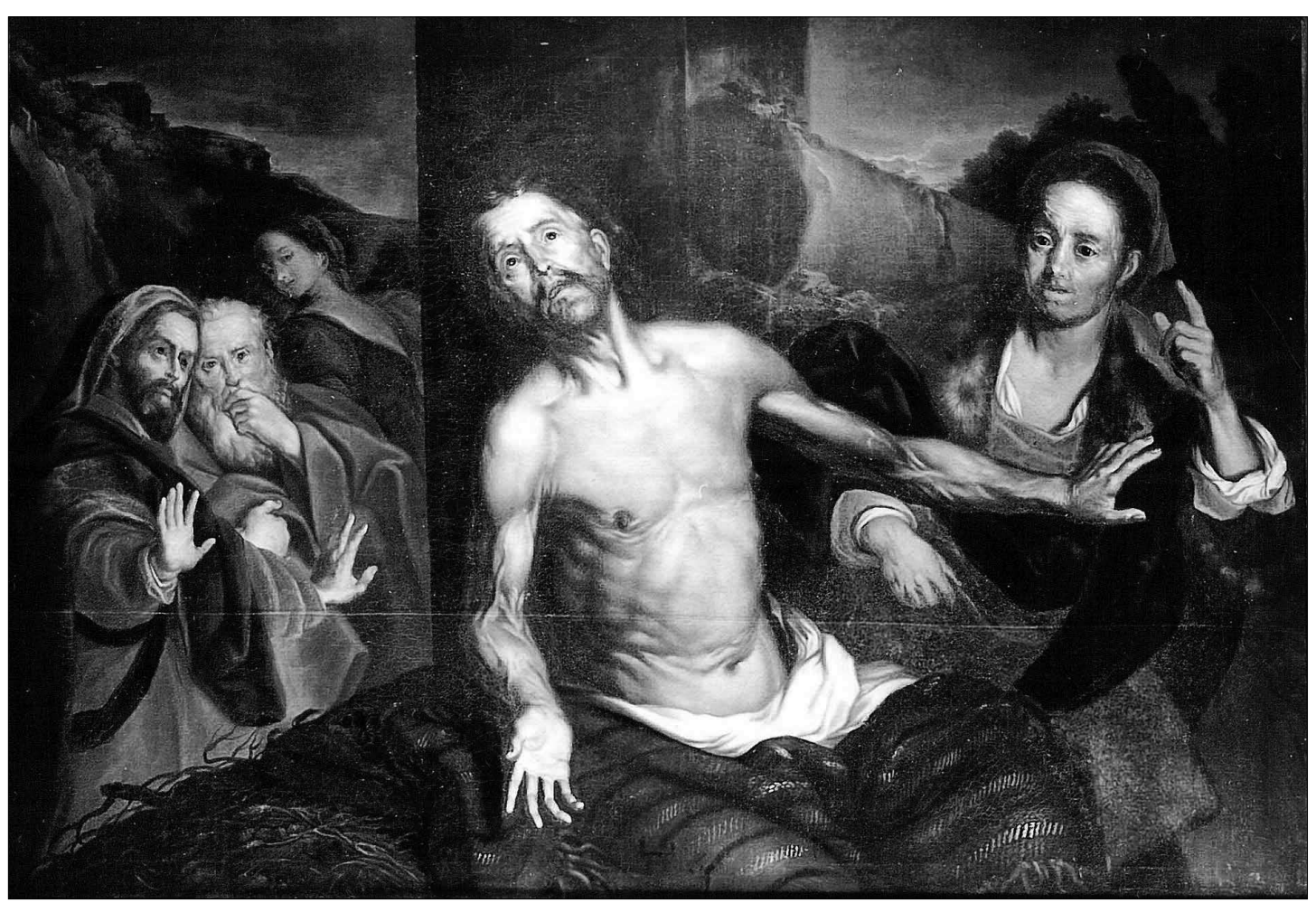

13. Franz Carl Remp, Hiob im Elend, Augustiner-Chorherrenstift St. Florian

Die einzelnen Gemälde zeichnen sich durch einen großen malerischen Reichtum aus, der von stofflich überzeugenden Teilen bis hin zu expressiv anmutenden skizzenhaften Details reicht. Besonders virtuos erscheint einerseits etwa das Kleid der hl. Kunigunde aus weißer Atlasseide; ein Vorzug des Künstlers, der sich bereits im Martyrium sowie im Schutzmantelbild der hl. Ursula ankündet und in der Enthauptung der hl. Barbara in der Wiener Peterskirche eine Fortsetzung findet. Ebenso bemerkenswerte Details finden sich bei den Gewändern der beiden weiblichen Figuren am rechten Bildrand in Der hl. Wolfgang unterrichtet die Kinder des Herzogs Heinrich von Bayern (Abb. 9 und 10). Andererseits sticht etwa die Partie um die Knie des hl. Bonifatius aufgrund ihrer effektvollen Skizzenhaftigkeit ins Auge (Abb. 11 und 12).

Weitere Aufträge für Deckenmalereien ereilten Remp aus dem Augustiner-Chorherrenstift St. Florian. Diese umfassen die Ausstattung des Treppenhauses und Räume in der Abfolge der Kaiserzimmer sowie in der Prälatur. Während er in den 1713/1714 entstandenen Werken dem für das Palais Attems charakteristischen Stil treu bleibt, vollzieht sich in den Arbeiten in der Prälatenhauskapelle, die er 1718 ausführte, ein Wandel. Sowohl der Engelssturz, als auch die Darstellungen der vier Evangelisten sind deutlich illusionistischer gestaltet. Im selben Jahr schuf er auch den Tod des hl. Joseph als Deckengemälde für das Schlafzimmer des Prälaten, das zwar wiederum dem Staffeleibild verhaftet ist, sich jedoch durch eine gesteigerte Expressivität auszeichnet. Dementsprechend ist eine weitere Phase der künstlerischen Reifung während der Wiener Jahre zu attestieren. Diese macht sich bereits in den drei Supraportengemälden für das Stift St. Florian aus dem Jahr 1714 bemerkbar, die eine deutliche Weiterentwicklung gegenüber vergleichbaren Werken für das Palais Attems zeigen. Der Wechsel von einer gleichmäßigen Helligkeit zu einem stärker ausgeprägten Helldunkel verleiht den Darstellungen formal eine größere Leuchtkraft und inhaltlich eine gesteigerte Dramatik. Betrachtet man den St. Florianer Hiob im Elend (Abb. 13) etwa vergleichend mit 


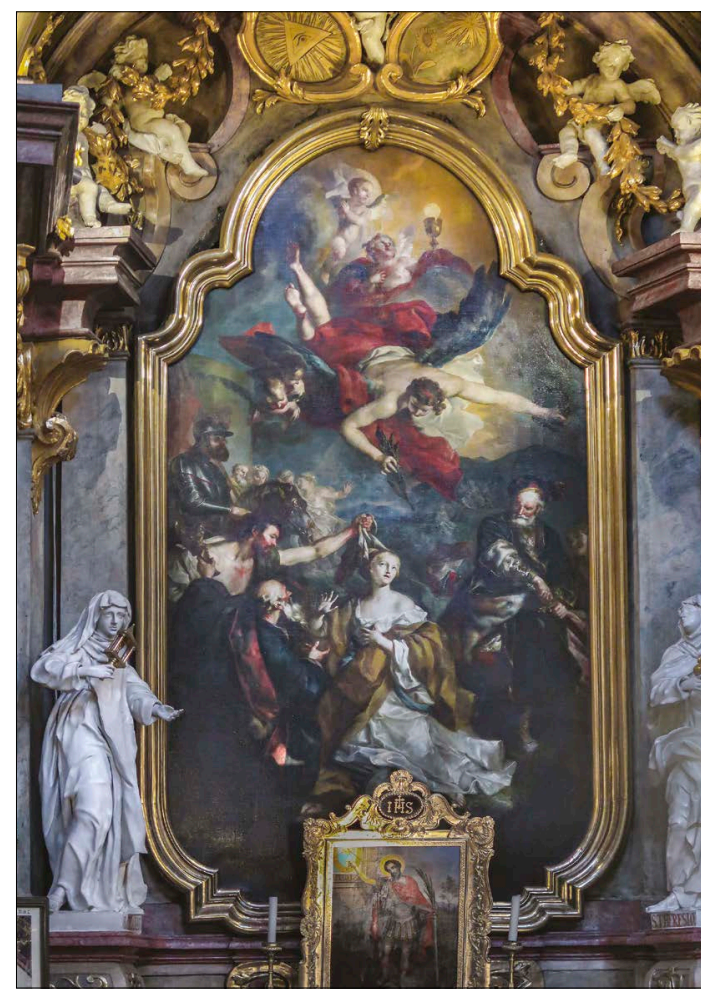

14. Franz Carl Remp, Enthauptung der hl. Barbara, Peterskirche, Wien
Lot und seine Töchter (Abb. 7), so ist einerseits die Weiterentwicklung deutlich abzulesen, andererseits besteht aber auch eine Ähnlichkeit, die für das Grazer Bild einen Entstehungszeitpunkt gegen Ende der Tätigkeit für den Grafen Attems nahelegt.

Es zeigt sich, dass Remp die während seines Italienaufenthaltes akkumulierten Kenntnisse in seinen Werken sukzessive zur Entfaltung brachte. Mit dem Umzug nach Wien, wo es im Vergleich zu Graz eine größere wie vielfältigere Kunstszene gab, boten sich ihm neue Möglichkeiten, aber auch Herausforderungen. Nach Jahren der exklusiven Tätigkeit für einen Auftraggeber musste sich der Künstler nun gleichsam auf dem freien Markt als Selbstständiger etablieren. Auf seinen Stil wirkte sich das visuell größere Angebot der Haupt- und Residenzstadt durchaus positiv aus. Mit Peter Strudel (um 1660-1714) und Johann Michael Rottmayr (1656-1730) waren dort auch zwei prominente Vertreter der Loth-Schule tätig. Wurde Remp in älteren Publikationen zwar immer wieder dieser Richtung zugeordnet, so zeigt sich gerade in den Wiener Jahren sei-

ne weitgehende Unabhängigkeit davon. Darüber hinaus waren hier auch niederländische Künstler ansässig, was wohl nicht ohne Auswirkungen auf Remp geblieben ist, ${ }^{37}$ denn gerade in seiner Wiener Zeit kommt es noch zu einer Steigerung des Helldunkels wie auch der Stofflichkeit. Die Protagonistinnen und Protagonisten der einzelnen Darstellungen erscheinen nun in der Regel in gleißendem Licht, was sich insbesondere an den Supraportengemälden für das Stift St. Florian sowie am Seitenaltarbild mit der Enthauptung der hl. Barbara für die Wiener Peterskirche (Abb. 14) beobachten lässt.

Charakteristisch für Remps gesamtes Schaffen bleiben die Auffassung männlicher Figuren mit massivem, beinahe tonnenförmigem Oberkörper sowie die eleganten Gesichtszüge mit feinen, leicht zugespitzten Nasen.

Während seiner Jahre in Slowenien und Graz konnte Franz Carl Remp wohl eher Aufsehen erregen als während seiner Zeit in Wien, wo die Konkurrenz für ihn größer war. Doch gerade diese künstlerische Dichte und Vielfalt scheint ihn gleichermaßen herausgefordert und beflügelt zu haben, sodass sein früher Tod umso mehr zu beklagen ist.

37 Vgl. Wolfgang PROHASKA, Franz Carl Remp (1674-1718), Samson und Dalila, Barock (Hrsg. Hellmut Lorenz), München-London-New York 1999 (Geschichte der bildenden Kunst in Österreich, 4), S. 421-422, Kat. Nr. 157. 


\section{Bibliographie}

Archivalische Vorarbeiten zur Österreichischen Kunsttopographie. Gerichtsbezirk und Stift Kremsmünster, 1-2 (Hrsg. Willibrord Neumüller), Wien 1961.

CEVC, Anica, Freske Matthiasa von Görza v Marijini cerkvi v Zagorju pri Podčetrtku, Zbornik za umetnostno zgodovino, n. F. 16, 1980, S. 53-73.

CORETH, Anna, Liebe ohne Maß. Geschichte der Herz-Jesu-Verehrung in Österreich im 18. Jahrhundert, Maria Roggendorf 1994 (Cor ad cor. Schriften im Dienst der Herz-Jesu-Verehrung, 4).

Die Kunstdenkmäler der Stadt Graz. Die Profanbauten des I. Bezirkes. Altstadt (Bearb. Wiltraud Resch), Graz 1996 (Österreichische Kunsttopographie, 53).

DORN, P. Theophil, Abriß der Baugeschichte Kremsmünsters, Heimatgaue. Zeitschrift für oberösterreichische Geschichte, Landes- und Volkskunde, 10/4, 1929, S. 209-244.

Graz (Bearb. Horst Schweigert), Horn-Wien 1979 (Dehio-Handbuch. Die Kunstdenkmäler Österreichs).

HAUPT, Herbert, Das Hof- und hofbefreite Handwerk im barocken Wien 1620 bis 1770. Ein Handbuch, Wien-Innsbruck 2007 (Forschungen und Beiträge zur Wiener Stadtgeschichte, 46).

Heilige Margareta Maria Alacoque. Leben und Offenbarungen von ihr selbst geschrieben und ergänzt durch Zeitgenossen, Freiburg $1984^{3}$.

Die Kunstdenkmäler der Stadt Graz. Die Profanbauten des I. Bezirkes. Altstadt (Bearb. Wiltraud Resch), Graz 1996 (Österreichische Kunsttopographie, 53).

Die Kunstdenkmäler des Benediktinerstiftes Kremsmünster. 1: Das Stift - Der Bau und seine Einrichtung (Bearb. Erika Doberer), Wien 1977 (Österreichische Kunsttopographie, 43).

LAVRIČ, Ana, Bratovščine v klariških samostanih na Kranjskem. Njihova umetnostna in duhovna dediščina, Acta historiae artis Slovenica, 25/1, 2020, S. 27-62.

LECHNER, Georg Matthias, Der Barockmaler Franz Carl Remp. 1675-1718, Wien 2010 (unpublizierte Dissertation).

LUBEJ, Uroš, Prispevki k biografijam na Kranjskem delujočih flamskih in holandskih slikarjev druge polovice XVII. stoletja, Acta historiae artis Slovenica, 2, 1997, S. 33-52.

MEERAUS, Robert, Zur Barockausstellung im Landesmuseum „Joanneum“ in Graz, Der Cicerone. Halbmonatsschrift für Künstler, Kunstfreunde und Sammler, 16, 1924, S. 415-416.

MOSER, Karl, Die Welsche Kirche in Graz, Wien-Graz-Leipzig 1928 (Kunstdenkmäler der Steiermark, 1).

MUROVEC, Barbara, Antonio Maderni. Je bil pozabljeni Weissenkircherjev zet iz Capolaga prvi Attemsov freskant?, Slovenska umetnost in njen evropski kontekst (Hrsg. Barbara Murovec), Ljubljana 2007, S. 114-122.

MUROVEC, Barbara, Historizirana podoba naročnika. Attemsova družinska portreta in Rembov avtoportret iz brežiškega gradu, Acta historiae artis Slovenica, 23/1, 2018, S. 113-131.

PROHASKA, Wolfgang, Franz Carl Remp (1674-1718), Samson und Dalila, Barock (Hrsg. Hellmut Lorenz), München-London-New York 1999 (Geschichte der bildenden Kunst in Österreich, 4), S. 421-422, Kat. Nr. 157.

RESMAN, Blaž, O nekaterih starejših radovljiških likovnih umetnikih, Radovljiški zbornik 1995, Radovljica 1995, S. 175-194.

RESMAN, Blaž, Šentjakobska cerkev v 18. stoletju, Jezuitski kolegij v Ljubljani (1597-1773). Zbornik razprav (Hrsg. Vincenc Rajšp), Ljubljana 1998 (Redovništvo na Slovenskem, 4), S. 189-228.

RESMAN, Blaž, „Podpisi“ svetnih naročnikov na sakralnih umetninah, Profano v sakralnem. Študije o vizualizaciji posvetnih teženj in motivov v cerkveni umetnosti (Hrsg. Mija Oter Gorenčič), Ljubljana 2019, S. 131-145.

SCHMITZ, Ida, Kirche und Kloster der Ursulinen in Graz. Ein Beitrag zur steiermärkischen Kunstgeschichte, Graz 1927 (unpublizierte Dissertation). 
STESKA, Viktor, Štiri pisma župnika Franca Avsca, Zbornik za umetnostno zgodovino, 22/1-2, 1944, S. 137-141.

ŠERBELJ, Ferdinand, Bistriški grad, Slovenska Bistrica 2005.

ŠERBELJ, Ferdinand, Ovalne slike Frančiška Karla Remba v Viteški dvorani brežiškega gradu, Litterae pictae. Scripta varia in honorem Nataša Golob septuagesimum annum feliciter complentis (Hrsg. Tine Germ, Nataša Kavčič), Ljubljana 2017, S. 379-393.

THALNITSCHER, Ioannes Gregorius, Annales Urbis Labacensis. Das ist Laybacherische Jahrsgeschichten Von An[no] 1660, bis 1700. Continuiert von an[no] 1700 bis 1718, Semeniška knjižnica, Ljubljana, rkp. 11.

THALNITSCHER, Ioannes Gregorius, Ectypon Bibliothecae Publicae Labacensis, 1715, Semeniška knjižnica, Ljubljana, rkp. 14.

VIDMAR, Polona, / .../ weilen es in der Welt was Seltsames sie bei dieser Zeit eine andächtige Seel zu finden, die ein Kloster stiften wollte /.../. Marija Terezija grofica Leslie in ustanovitev samostana elizabetink v Gradcu, Profano v sakralnem. Študije o vizualizaciji posvetnih teženj in motivov v cerkveni umetnosti (Hrsg. Mija Oter Gorenčič), Ljubljana 2019, S. 203-240.

WARTINGER, Joseph, Aeltere plastische Künstler in Steyermark, Steyermärkische Zeitschrift, 11, 1833, S. $97-100$.

WEIGL, Igor, Matija Persky. Arhitektura in družba sredi 18. stoletja, Ljubljana 2000 (unpublizierte Magisterarbeit).

WEIGL, Igor, „Die Einheimischen bewundern die Gemälde“. Graf Ignaz Maria von Attems-

Heiligenkreuz als Auftraggeber und Sammler, Kunsthistoriker, 18/19, 2001/2002 (2003), S. 50-55.

\section{Abbildungsnachweis}

1-2: ๑ ZRC SAZU, Umetnostnozgodovinski inštitut Franceta Steleta, Ljubljana (Foto: Andrej Furlan).

3: Alte Meister. Kunstauktion im Palais Dorotheum, Wien 1994.

4-5, 8-12, 14: Georg Lechner.

6: () Belvedere, Wien.

7: (๑) Universalmuseum Joanneum, Graz (Foto: Nicolas Lackner).

13: () Wien, Bundesdenkmalamt, Fotoarchiv. 


\title{
Frančišek Karel Remb med Gradcem in Dunajem
}

\author{
Povzetek
}

Kakor je pri baročnih umetnikih dovolj pogosto, lahko tudi življenjepis Frančiška Karla Remba, krščenega 14. oktobra 1675 v Radovljici, orišemo le z občutnimi vrzelmi. Gotovo je, da je bil slikar, ki se je na začetku učil pri svojem očetu Janezu Juriju Rembu, leta 1694 na potovanju, saj je arhivsko izpričana podpora, ki so mu jo za to odobrili kranjski deželni stanovi. Četudi cilj njegove poti v dokumentu ni imenovan, lahko domnevamo, da je mladi slikar za daljši čas odpotoval v Italijo; nazadnje je bilo arhivsko potrjeno, da je leta 1696 bival v Rimu.

Listine in matične knjige dokazujejo, da je med letoma 1707 in 1710 živel v Gradcu, kamor pa bi bil lahko prišel že nekaj let prej, potem ko je 1702/03 delal v Brežicah. Leta 1711, morda pa že 1710, se je z ženo Marijo Ludoviko preselil na Dunaj. V letih 1712 in 1713 je izvršil lepo število slik za benediktinski samostan Kremsmünster, med letoma 1713 in 1718 pa je dobil tudi več naročil iz samostana avguštinskih kanonikov St. Florian. Sicer pa je doslej znanih le malo drugih del iz umetnikovih poznejših let.

Med najzgodnejša znana Rembova dela sodi slika Srce Jezusovo, hranjena v nadškofijski palači v Ljubljani. Izvira iz samostana ljubljanskih klaris, ki so že leta 1702 zaprosile za dovoljenje, da ustanovijo bratovščino Srca Jezusovega. Slika, za katero je Remb kot predloge uporabil bratovščinske podobice, je tako zelo verjetno nastala v času neposredno pred slikarjevo selitvijo v Gradec.

Približno v istem času je Remb s freskami poslikal slavnostno dvorano v Brežicah. Nesporno slogovno heterogenost fresk najbrž lahko pojasnimo s tem, da je predstavljalo veliko naročilo, ki ga je mladi umetnik dobil, potem ko se je s študijskega potovanja vrnil poln različnih vtisov, (pre)velik izziv za njegovo samostojnost. Tako stropa ni enotno iluzionistično oblikoval, ampak na njem enega ob drugem sestavil posamezne prizore. To lastnost opazimo tudi še pozneje; Remb je vse življenje ostal zavezan klasični štafelajni sliki in se je v tako velikem merilu le stežka znašel. Precej bolj dovršenih se nasprotno zdi šest ovalnih slik, ki so bile prvotno vključene v poslikavo sten slavnostne dvorane v Brežicah; gre za alegorične upodobitve in dva družinska portreta.

Dela, ki jih je Remb ustvaril za palačo Attems na graški Sackstraße, so številčna in raznolika, od fresk preko stropnih in historičnih slik velikega formata ter supraport do slik, ki niso bile del opreme, ampak že spočetka vključene v Attemsovo zbirko. Žal je bil sčasoma precejšen del slik iz palače odtujen. Notranjščino so gotovo močno zaznamovale historične in alegorične podobe velikega formata, katerih del je danes v Stari galeriji Univerzalnega muzeja Joanneum v Gradcu.

Ob primerjavi del, ki se nahajajo v palači Attems ali pa so bila zanjo ustvarjena, se razkrije heterogena podoba. Glede na to, da so nastajala več let, verjetno šest do osem, moramo razlike vsekakor razumeti tudi kot rezultat slikarjevega razvoja. Prav na supraportah za palačo Attems lahko opazujemo vse večji poudarek na podajanju prostora. Drugo razlago za heterogenost v izvedbi moramo gotovo iskati v tem, da so bile posamezne slike izvršene $\mathrm{z}$ različno mero pozornosti glede na to, kam naj bi jih namestili.

$\mathrm{V}$ slikarjevo graško obdobje lahko po dosedanjem vedenju umestimo pet del, ki niso povezana s palačo Attems. Sliki Mučeništvo sv. Uršule v stranskem oltarju nekdanje uršulinske, zdaj cerkve Sv. Trojice na graški Sackstraße in Sv. Uršula zavetnica s plaščem v graškem uršulinskem samostanu sta bili verjetno darili Ignaca Marije grofa Attemsa sosednji redovni skupnosti. Sliko v velikem oltarju Welsche Kirche na Griesplatzu v Gradcu, ki predstavlja Sv. Frančiška Paolskega, bi smeli prav tako povezati z grofom Attemsom. Nepojasnjene pa ostajajo zveze z župnijsko, nekdaj karmeličansko cerkvijo v Voitsbergu, kjer nosi slika Smrt sv. Jožefa v velikem oltarju Rembov podpis, in z nekdanjim samostanom avguštinskih kanonikov v Stainzu, kjer lahko Rembu pripišemo sliko Sv. Avguština v desnem stranskem oltarju. 
Razločen razvojni napredek v primerjavi s temi slikami kaže Sv. papež in mučenik Aleksander iz leta $1712 \mathrm{v}$ benediktinskem samostanu Kremsmünster. Poleg tega dela in dveh slik za stranska oltarja v samostanski cerkvi je Remb za Kremsmünster ustvaril še cikel 13 historičnih slik, ki prikazujejo zgodbo o ustanovitvi in svetnike, pomembne za samostan. Posamezne slike se odlikujejo z veliko slikarsko veščino, ki sega od prepričljivo podane snovnosti do ekspresivno občutenih detajlov.

Nadaljnja naročila za stropne slikarije je Remb dobil iz samostana avguštinskih kanonikov St. Florian. Obsegale so poslikavo monumentalnega stopnišča ter prostorov ob cesarskih sobanah in v prelaturi.

Če povzamemo, lahko v Rembovih dunajskih letih potrdimo nadaljnje umetniško zorenje. Opazno je že na treh supraportah za samostan St. Florian iz leta 1714, ki kažejo razločen napredek v primerjavi s sorodnimi deli za palačo Attems. 